\title{
ARTICLE OPEN \\ Spinal cord injury reprograms muscle fibroadipogenic progenitors to form heterotopic bones within muscles
}

Hsu-Wen Tseng ${ }^{1}$, Dorothée Girard ${ }^{2}$, Kylie A. Alexander ${ }^{1}$, Susan M. Millard ${ }^{1}{ }^{1}$, Frédéric Torossian ${ }^{3}$, Adrienne Anginot ${ }^{3}$, Whitney Fleming ${ }^{1}$, Jules Gueguen $\mathbb{D}^{2}$, Marie-Emmanuelle Goriot ${ }^{2}$, Denis Clay ${ }^{4}$, Beulah Jose ${ }^{1}$, Bianca Nowlan (D) ${ }^{1}$, Allison R. Pettit ${ }^{1}$, Marjorie Salga ${ }^{5,6}$, François Genêt ${ }^{5,6}$, Marie-Caroline Le Bousse-Kerdilès ${ }^{3}$, Sébastien Banzet ${ }^{2 凶}$ and Jean-Pierre Lévesque (iD ${ }^{1 凶}$

The cells of origin of neurogenic heterotopic ossifications (NHOs), which develop frequently in the periarticular muscles following spinal cord injuries ( $\mathrm{SCls}$ ) and traumatic brain injuries, remain unclear because skeletal muscle harbors two progenitor cell populations: satellite cells (SCs), which are myogenic, and fibroadipogenic progenitors (FAPs), which are mesenchymal. Lineage-tracing experiments using the Cre recombinase/LoxP system were performed in two mouse strains with the fluorescent protein ZsGreen specifically expressed in either SCs or FAPs in skeletal muscles under the control of the Pax7 or Prrx1 gene promoter, respectively. These experiments demonstrate that following muscle injury, SCl causes the upregulation of PDGFRa expression on FAPs but not SCs and the failure of SCs to regenerate myofibers in the injured muscle, with reduced apoptosis and continued proliferation of muscle resident FAPs enabling their osteogenic differentiation into NHOs. No cells expressing ZsGreen under the Prrx 1 promoter were detected in the blood after injury, suggesting that the cells of origin of NHOs are locally derived from the injured muscle. We validated these findings using human NHO biopsies. PDGFRa ${ }^{+}$ mesenchymal cells isolated from the muscle surrounding $\mathrm{NHO}$ biopsies could develop ectopic human bones when transplanted into immunocompromised mice, whereas $\mathrm{CD}_{5} 6^{+}$myogenic cells had a much lower potential. Therefore, $\mathrm{NHO}$ is a pathology of the injured muscle in which $\mathrm{SCl}$ reprograms FAPs to undergo uncontrolled proliferation and differentiation into osteoblasts.

Bone Research (2022)10:22 ; https://doi.org/10.1038/s41413-022-00188-y

\section{INTRODUCTION}

Neurogenic heterotopic ossifications (NHOs) are pathological heterotopic bones that develop in peri-articular muscles ${ }^{1,2}$ following severe lesions of the central nervous system (CNS), such as spinal cord injuries (SCls), traumatic brain injuries, strokes and cerebral anoxia. NHOs are frequent, with an incidence of $10 \%-23 \%$ in patients with traumatic brain injury and $10 \%-53 \%$ in patients with SCls, increasing to $68 \%$ in victims of severe combat blast injuries involving the spine. ${ }^{3-8}$ NHOs develop most frequently at the hip, elbow, knee and shoulder. ${ }^{2,9}$ Because of their large size, NHOs are highly incapacitating, causing substantial pain and a gradual reduction in the range of motion of affected limbs, often progressing to complete ankylosis. ${ }^{2,9}$ This process exacerbates functional disabilities by increasing the difficulty in sitting, eating and dressing..$^{10} \mathrm{NHO}$ growth can also cause nerve and blood vessel compression, further increasing patient morbidity. ${ }^{11,12}$ Although this pathology has been known for just over 100 years, treatment is currently limited to surgical resection after $\mathrm{NHOs}$ have matured, ${ }^{2,10,13,14}$ a procedure that is challenging, particularly when ossifications entrap the whole joint and adjacent large blood vessels and nerves. The development of improved treatments for $\mathrm{NHOs}$ has been slow, and trials of pharmacological interventions have continued to show limited effectiveness, ${ }^{15,16}$ reflecting the current limited knowledge on the etiology, pathogenesis and pathobiology of NHOs. Indeed, the initial causal mechanisms that trigger NHOs are unique to this pathology, as they involve severe CNS trauma ${ }^{17,18}$ rather than other forms of trauma, such as body burns, or activating mutations of osteogenic genes, such as bone morphogenetic protein type I receptor $A C V R 1$, in fibrodysplasia ossificans progressiva (FOP). ${ }^{17}$ Therefore, it is essential to uncover the mechanisms of $\mathrm{NHO}$ pathogenesis to identify potential therapeutic targets and treatments that will reduce $\mathrm{NHO}$ development and remove the need for very invasive and delicate surgical resections. ${ }^{17}$

Our group previously reported the first mouse model of NHOs in which $\mathrm{NHOs}$ spontaneously develop when an $\mathrm{SCl}$ is combined with muscle injury without additional nonphysiological manipulations, such as the overexpression of bone morphogenetic protein (BMP) transgenes or the insertion of hyperactive mutants of BMP receptors. ${ }^{19}$ Our model revealed that $\mathrm{SCl}$ causes a further exacerbation of the inflammatory response in injured muscles with exaggerated Ly6C $C^{\text {bright }}$ inflammatory monocyte/macrophage infiltration and persistent accumulation of the inflammatory cytokine oncostatin M (OSM), leading to persistent activation of JAK1/2 tyrosine kinases and signal transducer and activator of transduction-3 (STAT3), which in turn promote NHOs instead of muscle repair. ${ }^{19-21}$

\footnotetext{
${ }^{1}$ Mater Research Institute-The University of Queensland, Woolloongabba, QLD, Australia; ${ }^{2}$ Institut de Recherche Biomédicale des Armées (IRBA), INSERM UMRS-MD, 1197 Clamart, France; ${ }^{3}$ INSERM UMRS-MD 1197, Université de Paris-Saclay, Hôpital Paul Brousse, Villejuif, France; ${ }^{4}$ INSERM UMS-44, Université de Paris-Saclay, Hôpital Paul Brousse, Villejuif, France; ${ }^{5} \mathrm{UPOH}$ (Unité Péri Opératoire du Handicap, Perioperative Disability Unit), Physical and Rehabilitation Medicine department, Raymond-Poincaré Hospital, Assistance Publique - Hôpitaux de Paris (AP-HP), Garches, France and ' ${ }^{6}$ Université de Versailles Saint Quentin en Yvelines, UFR Simone Veil - Santé, END:ICAP INSERM U1179, Montigny le Bretonneux, France

Correspondence: Sébastien Banzet (sebastien.banzet@inserm.fr) or Jean-Pierre Lévesque (jean-pierre.levesque@mater.uq.edu.au)

These authors contributed equally: Hsu-Wen Tseng, Dorothée Girard, Kylie A. Alexander
}

Received: 26 June 2020 Revised: 21 November 2021 Accepted: 6 December 2021

Published online: 25 February 2022 
How injured skeletal muscles generate heterotopic bones instead of regenerating functional myofibers following severe lesions of the CNS remains a fascinating stem cell biology question and may reveal novel therapeutic strategies to treat NHOs. ${ }^{17,18}$ Adult skeletal muscles contain two populations of stem/progenitor cells: (1) satellite cells (SCs), residing within the myofiber under the myofiber basal lamina, which regenerate myoblasts and myocytes following injury and are as such true muscle stem cells, ${ }^{22-24}$ and (2) fibroadipogenic progenitors (FAPs) residing in the interstitial space between myofibers. ${ }^{25}$ Unlike SCs, FAPs are of mesenchymal origin and do not regenerate myoblasts. ${ }^{25}$ Muscle repair following injury is a highly orchestrated process that involves the coordinated recruitment of both SCs and FAPs as well as macrophages. Upon muscle injury, FAPs proliferate transiently for the first 3 days in mice and then undergo apoptosis under the effect of tumor necrosis factor (TNF) released by infiltrating C-C chemokine receptor-2 $(\mathrm{CCR} 2)^{+}$inflammatory monocytes/macrophages, which also clear apoptotic FAPs. ${ }^{26,27}$ Both FAPs and macrophages are essential to orchestrate and complete appropriate myogenic repair from SCs, and the critical function of FAPs is thought to involve the secretion of appropriate growth factors and extracellular matrix, which enable SC proliferation, myogenic differentiation and myofiber assembly. ${ }^{25,28,29}$ As both muscle SCs and FAPs have osteogenic potential in vitro, ${ }^{19,21}$ the question of the cells of origin of $\mathrm{NHOs}$ has not been resolved.

Lineage-tracing experiments using the Cre-loxP system have been undertaken to identify which progenitors contribute to the inheritable genetic form of heterotopic ossification called fibrodysplasia ossificans progressiva (FOP). Unlike NHOs, which are frequent after severe CNS injury, FOP is an extremely rare disorder caused by a gain-of-function missense single nucleotide mutation in the bone morphogenetic protein (BMP) type I receptor gene $A C V R 1,{ }^{30}$ resulting in a switch in ligand preference with aberrant activation of BMP signaling by activin-A instead of BMPs. ${ }^{31}$ Most lineage tracing experiments to identify the "cells of origin" of heterotopic ossifications were performed in mouse models of FOP expressing either a Cre recombinase-inducible $A C V R 1^{\mathrm{R} 206 \mathrm{H}}$ mutant that causes FOP in humans or a BMP transgene or with the insertion of a BMP-containing implant. In these mouse models of FOP, a variety of gene promoters have been used to drive Cre recombinase expression. Based on Cre recombinase driven by the Pax7 (Paired Box 7) or Cdh5 (Cadherin 5) gene promoters, which are specific to SCs and endothelial cells, respectively, it was concluded that neither SCs nor endothelial cells were the cells of origin of heterotopic ossifications in FOP. ${ }^{32}$ However, most of the gene promoters used in similar studies (e.g., Glast/SIc1a3, Scx, Mx1, Tie2, CD133/Prom1 gene promoters) ${ }^{32-34}$ did not result in exclusive expression in mesenchymal progenitor cells, and the conclusion that FOP heterotopic ossifications were derived from mesenchymal cells was inferred by elimination of other possible cell candidates. In a mouse model of FOP with overexpression of a BMP4 transgene, it was recently shown that Gli1-expressing cells were integrated in HOs. ${ }^{34}$ However, BMP4 is a very strong osteogenic protein, and the relationship of the level of artificially high BMP4 expression by means of a transgene to $\mathrm{SCl}$ induced NHOs remains to be demonstrated. ${ }^{17,19}$ Recently, a Cre mouse model with the Pdgfra gene promoter was used to demonstrate that HOs induced by BMP-2-supplemented Matrige $^{35}$ or by overexpressing the FOP-causing $A C V R 1^{\mathrm{R} 206 \mathrm{H}}$ mutant $^{36}$ originated from mesenchymal cells expressing platelet-derived growth factor receptor-a (PDGFRa). However, while relevant models of FOP, artificial expression of osteogenic $A C V R 1^{\mathrm{R} 206 \mathrm{H}}$ or $A C V R 1^{\text {Q207D }}$ mutants or artificial overexpression of a BMP transgene or implantation of BMP-containing scaffolds utilized in these studies above are of little biological and clinical relevance to acquired NHOs developing after severe CNS injuries because $\mathrm{NHOs}$ occur with high prevalence in genetically normal patients of a broad range of ethnicities. In a mouse model of traumatic HOs induced by body burn and tenotomy and a model of FOP generated by induced Cre recombinase activation of the ACVR $1^{\text {Q207D }}$ activating mutation, it was found that both burninduced $\mathrm{HO}$ in the tendon and subcutaneous FOP-induced HOs were derived from Prrx 1 gene-expressing mesenchymal progenitors. ${ }^{37}$ However, these $\mathrm{HO}$ models do not involve severe CNS trauma, which defines and triggers NHOs. ${ }^{17,19}$ Furthermore, while FOP flare-ups develop in many different types of tissues associated with muscles (e.g., skeletal muscles, tendons, ligaments, fascia, and aponeuroses), ${ }_{1}^{38}$ possibly due to the dominant effect of activating mutations of ACVR1, NHOs are mostly intramuscular in otherwise genetically normal patients. ${ }^{1}$ Therefore, which progenitor cells within skeletal muscles are the "cells of origin" for $\mathrm{NHO}$ development after $\mathrm{SCl}$ remains to be established. To do so, we crossed a Cre-inducible fluorescent Zoanthus green (ZsGreen) reporter mouse strain with either a strain with Pax7CreET2-enabled specific expression in $\mathrm{SCs}^{39}$ or the Prrx1-Cre strain, which specifically expresses the Cre recombinase transgene in mesenchymal stem/progenitor cells under the control of the Prrx1 gene enhancer. ${ }^{40}$ Finally, we sorted $\mathrm{CD} 56^{+}$myogenic progenitors and PDGFRa-expressing mesenchymal progenitors from human skeletal muscle surrounding NHOs after surgical excision and studied their osteogenic differentiation in vitro and in vivo in an ectopic bone model in immunodeficient mice.

\section{RESULTS}

ZsGreen ${ }^{+}$cells identify SCs and FAPs in the muscles of Pax7-

CreERT2 and Prrx1-Cre mice

To determine whether NHOs are derived from muscle SCs and FAPs, we first assessed the specificity and efficiency of ZsGreen reporter expression in the Pax7-CreERT2; Rosa26-LoxP-STOP-LoxPZsGreen mice (abbreviated as Pax ${ }^{\mathrm{ZsG}}$ thereafter) and the Prrx1-Cre; Rosa26-LoxP-STOP-LoxP-ZsGreen mice (abbreviated as Prrx ${ }^{\mathrm{ZsG}}$ ) (Fig. 1a). CreERT2 was activated by daily gavage with tamoxifen for 4 days, after which mice were left to rest for an additional 2 weeks. The right hind limb hamstring muscle was then injected with cardiotoxin (CDTX) to cause muscle injury and initiate muscle regeneration. Fourteen days post-injury, muscles were harvested and dissociated for analyses of single muscle cell suspensions by flow cytometry (Fig. 1b). Within the CD45 $5^{-}$and hematopoietic lineage (Lin: Ter119, CD3E, CD45R, CD11b, Gr1)negative nonhematopoietic cell gate, endothelial cells were identified as $\mathrm{CD}_{3} 1^{+}$and stem cell antigen-1 (Sca1)-positive, SCs were identified as $\mathrm{CD}_{3} 1^{-} \mathrm{CD}_{3} 4^{+} \mathrm{Sca}^{-}$integrin a7 $\left(\right.$ITGA7) ${ }^{+}$ PDGFRa $^{-}$and FAPs were identified as $\mathrm{CD}_{3} 1^{-} \mathrm{CD}_{3}{ }^{+} \mathrm{Sca}^{+}$ ITGA7 $^{-}$PDGFRa $^{+}$(Fig. S1), in accordance with previous literature. $^{23,25,41}$ The frequencies of SCs $\left(\mathrm{CD} 31^{-} \mathrm{CD} 34^{+} \mathrm{Sca} 1^{-} \mathrm{ITGA}^{+}\right.$ PDGFRa $\left.{ }^{-}\right)$, FAPs $\left(\mathrm{CD}_{3} 1^{-} \mathrm{CD}_{3} 4^{+} \mathrm{SCa}^{+}{ }^{+} \mathrm{ITGA}^{-} \mathrm{PDGFRa}^{+}\right)$and endothelial cells $\left(\mathrm{CD} 31^{+} \mathrm{Sca} 1^{+}\right)$were similar between the CDTXinjured and noninjured muscles in both the $\operatorname{Pax}^{\mathrm{ZsG}}$ and $\operatorname{Pr} \mathrm{Pr} 1^{\mathrm{ZsG}}$ strains 14 days post-injury (Table S1).

We subsequently gated $\mathrm{ZsGreen}^{+}$cells within the hamstring muscles of these mice (Fig. 1c). In the vehicle-injected muscles of the $P a x 7^{\mathrm{ZsG}}$ mice, all $\mathrm{ZsGreen}^{+}$cells had the typical SC phenotype (CD45 ${ }^{-} \mathrm{Lin}^{-} \mathrm{CD} 31^{-} \mathrm{CD}_{4}{ }^{+} \mathrm{Sca}^{-}{ }^{-} \mathrm{ITGA} 7^{+} \mathrm{PDGFRa}^{-}$) with no ZsGreen ${ }^{+}$cells in the endothelial gate and very few in the FAP gate (Fig. 1d - PBS). In the CDTX-injured muscle, the distribution of $\mathrm{ZsGreen}^{+}$cells was similar but with the emergence of $\mathrm{CD}_{4} 5^{-} \mathrm{Lin}^{-} \mathrm{CD} 34^{-} \mathrm{Sca} 1^{-} \mathrm{ITGA}^{+} \mathrm{PDGFRa}^{-}$cells derived from ZsGreen ${ }^{+}$SCs (Fig. 1d-CDTX). These cells are likely differentiating myoblasts.

Conversely, in the vehicle-injected contralateral muscle of the Prrx $^{\mathrm{ZsG}}$ mice, most ZsGreen ${ }^{+}$cells had the typical FAP phenotype with no $\mathrm{ZsGreen}{ }^{+}$cells in the endothelial gate and very few in the typical SC gate (Fig. 1e PBS). The phenotypes of $\mathrm{ZsGreen}^{+}$cells were the same in the CDTX-injured muscle of the $\operatorname{Prrx} 1^{\mathrm{ZsG}}$ mice (Fig. 1e-CDTX). 
a
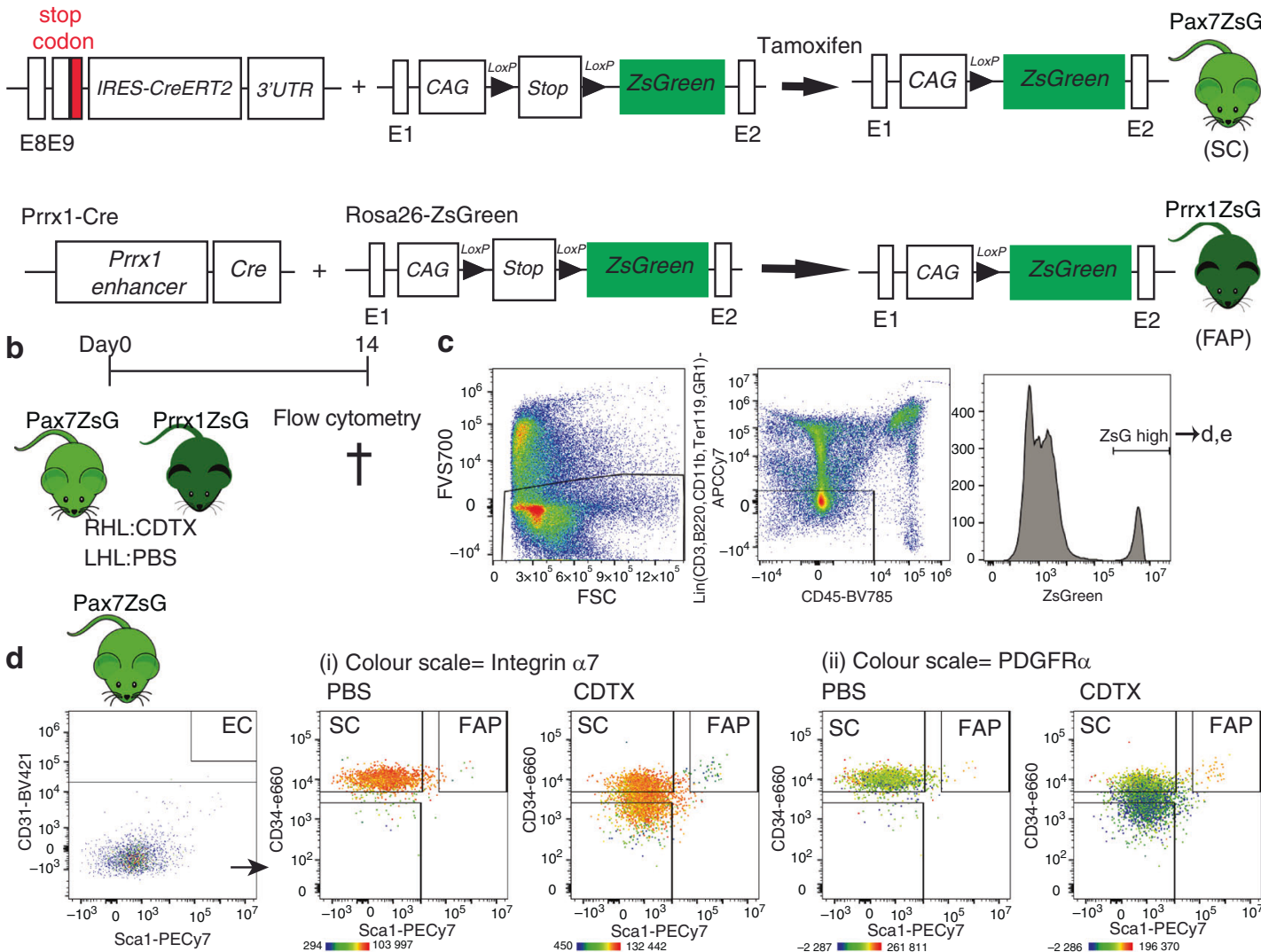

(i) Colour scale $=$ Integrin $\alpha 7$ PBS

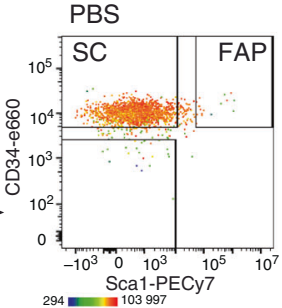

CDTX

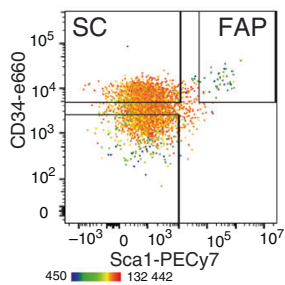

(ii) Colour scale $=$ PDGFR $\alpha$

PBS
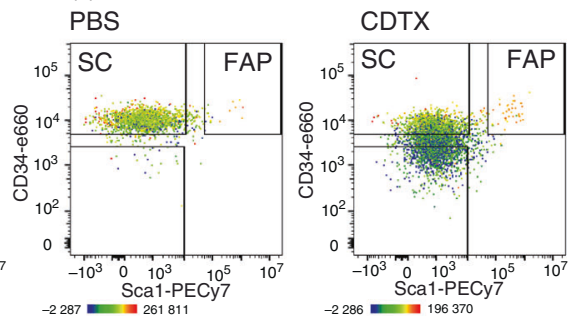

(ii) Colour scale $=$ PDGFR $\alpha$

\section{PBS}

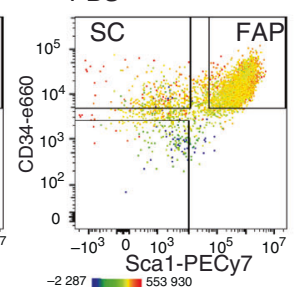

$-2287-$ Sca1-PE 553930
CDTX

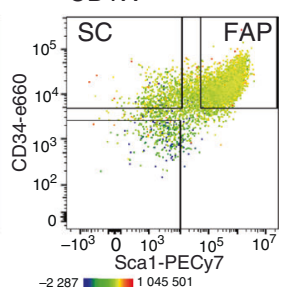

f
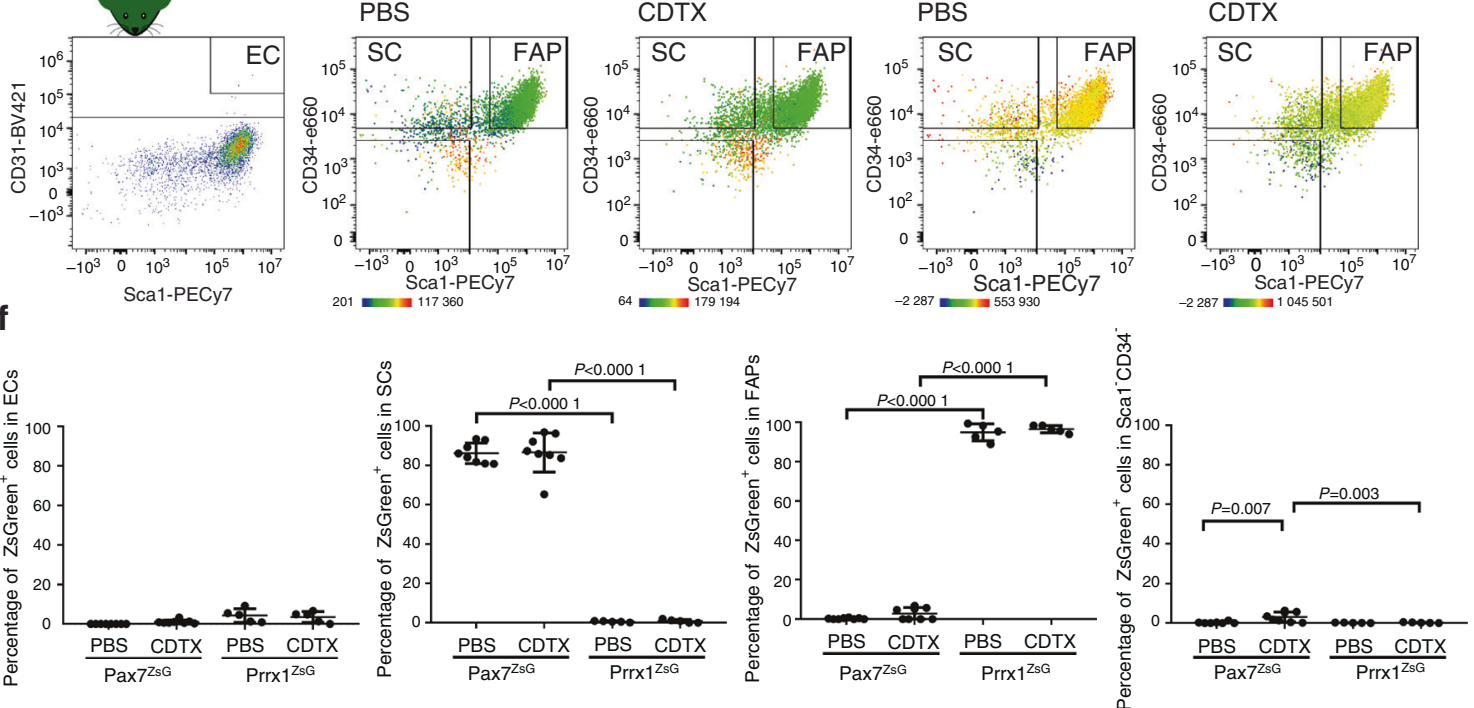

Fig. 1 ZsGreen labels SCs and FAPs in skeletal muscles of the Pax $7^{\mathrm{ZsG}}$ and Prrx $1^{\mathrm{ZsG}}$ mice, respectively. a Schematic representation of tamoxifen-inducible Cre-dependent ZsGreen reporter induction. b Pax $Z^{\mathrm{ZsG}}$ ( $n=4 /$ group) and Prrx $1^{\mathrm{ZsG}}$ ( $n=3 /$ group) mice were injected with CDTX in the hamstring muscle of the right hind limb (RHL) and PBS in the hamstring muscle of the left hind limb (LHL). Muscle cells were isolated 14 days after injection and subsequently stained for surface cell markers. c After gating on forward/side scatters and FVS700 dead cell exclusion, ZsGreen-high cells were gated from $\mathrm{Lin}^{-} \mathrm{CD} 45^{-}$nonhematopoietic population in both (d) Pax7 ${ }^{\mathrm{ZsG}}$ and (e) Prrx $1^{\mathrm{ZsG}}$ mice and further subgrouped into $\mathrm{CD} 31^{+} \mathrm{Sca} 1^{+}(\mathrm{EC}), \mathrm{CD} 31^{-} \mathrm{Sca} 1^{-} \mathrm{CD} 34^{+}(\mathrm{SCs}), \mathrm{CD} 31^{-} \mathrm{Sca} 1^{+} \mathrm{CD} 34^{+}$(FAPs), and Sca $1^{-} \mathrm{CD} 34^{-}$populations. The color indicates the expression level of (i) integrin $\alpha 7$ and (ii) PDGFR $\alpha$. Yellow-orange: high expression. Green: low expression. $\mathbf{f}$ Frequencies of ZsGreen ${ }^{+}$cells in

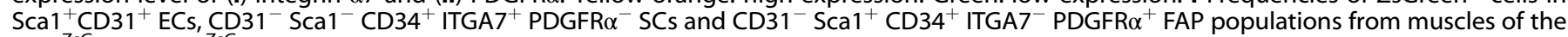
$\operatorname{Pax}^{\mathrm{ZsG}}$ and $\operatorname{Prrx}^{\mathrm{ZsG}}$ mice following the gating strategy in Fig. S1. Each dot represents a separate mouse, and bars are the mean \pm SD. The results of 8 mice per group were from 3 independent experiments performed over a period of 2 years with different flow cytometers. Significance was analyzed by one-way ANOVA with Tukey's multiple comparison test 
In addition to the high specificity of these lineage tracing strategies, the recombination efficiency was also very high, with over $90 \%$ of SCs and FAPs labeled in the muscle of the Pax $7^{\mathrm{ZsG}}$ and $\operatorname{Prrx} 1^{\mathrm{ZsG}}$ strains, respectively (Fig. 1f). Importantly, Cremediated recombination in the $\operatorname{Pax} 7^{\mathrm{ZsG}}$ and $\operatorname{Prrx}^{\mathrm{ZsG}}$ mice did not affect subsequent $\mathrm{NHO}$ development compared to that in the C57BL/6 mice, as measured by microcomputerized tomography $(\mu \mathrm{CT})$ or hematoxylin-eosin staining, which clearly showed the presence of necrotic and fibrotic muscle together with inflammatory infiltrate and sporadic bony nodules 28 days after injury in both strains, as we previously reported in C57BL/6 mice $13,20,21,42$ (Fig. S2). Altogether, these experiments confirmed that ZsGreen was specifically expressed in the targeted muscle cell populations in both the $\operatorname{Pax}^{\mathrm{ZsG}}$ and $\operatorname{Prrx}^{\mathrm{ZsG}}$ strains without altering $\mathrm{NHO}$ development, thus illustrating their suitability for lineage tracing of SCs and FAPs in vivo.

NHOs are not derived from Pax7-expressing SCs

ZsGreen expression was then examined on frozen longitudinal sections of uninjured muscle, repaired muscle and $\mathrm{NHOs}$ from the $\mathrm{Pax}^{\mathrm{ZsG}}$ mice (Fig. 2a). In noninjured muscles from the $\mathrm{Pax} 7^{\mathrm{ZsG}}$ mice, ZsGreen was expressed in a discrete population of small cells distributed along myofibers typical of SCs (Fig. 2b). Some myofibers were also ZsGreen ${ }^{+}$, likely reflecting their natural turnover from ZsGreen $^{+}$SCs over a period of 4 weeks after tamoxifen induction. Fourteen days after CDTX-induced muscle injury, in the absence of $\mathrm{SCl}$, all myofibers were $\mathrm{ZsGreen}^{+}$, as anticipated, illustrating muscle regeneration from $\mathrm{ZsGreen}^{+} \mathrm{SCs}$ (Fig. 2c).

In the cohort of mice that underwent spinal cord transection (SCI) and CDTX-mediated muscle injury, frozen sections were stained with specific anti-collagen I [Fig. 2d(i-ii)] and antiosteocalcin antibodies [Fig. $2 \mathrm{~d}$ (iii-iv)]. An example of a nonimmune lgG negative control for anti-collagen I and anti-osteocalcin antibodies is shown in Fig. $2 \mathrm{~d}(\mathrm{v})$. Immunohistofluorescence (IHF) confirmed $\mathrm{ZsGreen}^{+}$cells within areas of regenerating muscle that contained neoformed ZsGreen ${ }^{+}$myofibers. Most importantly, $\mathrm{ZsGreen}^{+}$cells were largely absent among areas of fibrotic muscle and $\mathrm{NHO}$ nodules. ZsGreen ${ }^{+}$cells were not intercalated among the collagen $\mathrm{I}^{+}$bone matrix or osteocalcin ${ }^{+}$osteoblasts on $\mathrm{NHO}$ nodules. Quantification of NHOs through four different $\mathrm{Pax} 7^{\mathrm{ZsG}}$ mice showed that none of the 44 osteocalcin ${ }^{+}$NHOs contained $\mathrm{ZsGreen}^{+}$cells (Fig. 2e). This finding demonstrates that $\mathrm{NHOs}$ following $\mathrm{SCl}$ are not derived from $\mathrm{ZsGreen}^{+} \mathrm{SCs}$.

NHOs are derived from Prrx1-expressing FAPs

ZsGreen expression was also examined on frozen longitudinal sections of uninjured muscle, repaired muscle and NHOs from the Prrx $1^{\mathrm{ZsG}}$ mice (Fig. 3a). In the uninjured muscle, reticulated $\mathrm{ZsGreen}^{+}$cells were scattered in the interstitium along myofibers (Fig. 3b), a typical distribution and morphology of FAPs. ${ }^{25}$ Importantly, in the regenerating CDTX-injured muscle (without $\mathrm{SCl}), \mathrm{ZsGreen}^{+}$cells were distributed similarly, and most importantly, they did not contribute to neoformation of myofibers (Fig. 3c), in concordance with the literature. ${ }^{25}$

The Prrx $1^{\mathrm{ZsG}}$ mice that underwent $\mathrm{SCl}$ and $\mathrm{CDTX}$-mediated muscle injury also developed $\mathrm{NHOs}$ (similar to $\mathrm{Pax} 7^{\mathrm{ZsG}}$ mice that underwent the same treatment) (Fig. S2). However, in sharp contrast to those of the $P a x 7^{\mathrm{ZsG}}$ mice, all fibrotic areas in the $\mathrm{SCl}+$ CDTX-injured muscles of the Prrx $1^{\mathrm{ZsG}}$ mice were intensely labeled by ZsGreen, particularly around collagen $\mathrm{I}^{+}$and osteocalcin ${ }^{+} \mathrm{NHO}$ nodules [Fig. 3d(ii-x)]. We counted 30 osteocalcin ${ }^{+}$NHOs from three Prrx $1^{\mathrm{ZsG}}$ mice, and all of them were intercalated with $\mathrm{ZsGreen}{ }^{+}$cells (Fig. 2e). At higher magnification, differentiating osteocalcin ${ }^{+}$ osteoblasts (red) were also $\mathrm{ZsGreen}^{+}$[Fig. 3d(vii-x) circles], suggesting that $\mathrm{NHOs}$ are derived from Prrx1-expressing mesenchymal progenitor cells rather than SCs. To confirm that NHOs are formed from Prrx 1-expressing FAPs and not by Pax7-expressing SCs, we performed Fisher's exact test on all NHO nodules manually counted on tissue sections from $4 \mathrm{Pax}^{\mathrm{ZsG}}$ mice and $3 \operatorname{Prrx}^{\mathrm{ZsG}}$ mice (Fig. 2e). The absence/presence of ZsGreen in $\mathrm{NHO}$ nodules from these 2 strains was significantly different $\left(P<10^{-4}\right)$. An additional Fisher's exact test detected ZsGreen fluorescence in NHOs of 3 mice of the $3 \operatorname{Prrx}^{\mathrm{ZsG}}$ mice containing NHOs, whereas ZsGreen was absent from all NHOs in the 4 Pax $7^{\mathrm{ZsG}}$ mice, which demonstrated that ZsGreen was differentially distributed in the $\mathrm{NHOs}$ from the two strains $(P=0.0286)$. Together, these results show that NHOs are derived from Prrx1-expressing mesenchymal progenitor cells but not from SCs.

Mesenchymal Prrx $1^{+}$cells do not circulate in blood after SCl Parabiosis models have been previously used to track circulating cells that contribute to heterotopic ossifications (HOs). A ubiquitous green fluorescent protein (GFP) reporter mouse was joined with a wild-type mouse, with the wild-type mouse receiving Achilles tendon tenectomy and dorsal burn injury to induce $\mathrm{HO}$ formation. Circulating $\mathrm{GFP}^{+}$cells from the GFPexpressing parabiont contributed to $\mathrm{HO}$ development in the wild-type parabiont 28 days after tenectomy and burn injury. ${ }^{43}$ However, a more recent parabiosis study suggests otherwise: $\mathrm{HO}$ induced by inserting BMP2-supplemented Matrigel matrix did not contain cells derived from PDGFRa ${ }^{+}$FOPs recruited from the other parabiont via the shared circulation, suggesting that the cells of origin of BMP2-induced HOs are not recruited via the circulation. ${ }^{35}$

To clarify the dichotomy of these two previous publications, we first investigated whether $\mathrm{SCl}$ activates the expression of osteogenic BMPs and BMP signaling in injured muscles. $\mathrm{SCl}$ did not increase the expression of Bmp2, Bmp4 or Bmp7 RNA in paraplegic hindlimb muscles (Fig. S3a). In contrast, either $\mathrm{SCl}$ or muscle injuries decreased the expression of osteogenic BMPs. We also investigated the effect of daily treatment with LDN-193189, a potent inhibitor of BMP type I receptor serine kinases that has been shown to be effective at inhibiting $\mathrm{HO}$ development in the mouse FOP model driven by the $A C V R 1^{\mathrm{Q} 207 \mathrm{D}}$ missense mutation ${ }^{44}$ and in the burn-induced rat model of ossifying tendinopathy. ${ }^{45}$ While LDN-193189 significantly inhibited mineralization of mouse bone marrow-derived mesenchymal stromal cells (BM-MSCs) cultured in osteogenic conditions (Fig. S3b), treatment of mice with LDN-193189 either in the first two weeks of the injury or during the maturation phase of NHOs between weeks 2 and 3 post-injury had no effect on NHO development (Fig. S3c-d). As BMPs are known to induce endochondral ossification, we stained sections of CDTX-injured muscles at days 7, 14 and 21 following $\mathrm{SCl}$ with safranin $\mathrm{O}$ to span the time course of $\mathrm{NHO}$ development in mice (Fig. S4). Although occasional mast cells brightly stained by safranin $\mathrm{O}$ could be detected in the developing $\mathrm{NHO}$, there was no evidence of cartilage matrix in any $\mathrm{NHO}$ examined at any time point ( $n=$ mice per time point). Therefore, unlike the $A C V R 1^{\text {Q207D }}$ FOP model and the burn-induced ossifying tendinopathy model, the BMP signaling inhibitor LDN-193189 was unable to reduce $\mathrm{NHO}$ development after $\mathrm{SCl}$, suggesting that $\mathrm{NHO}$ development following $\mathrm{SCl}$ is not as BMP-dependent as the two other processes of $\mathrm{HO}$ development and does not involve endochondral ossification.

We next investigated whether Prrx $1^{+}$mesenchymal cells at the origin of $\mathrm{NHOs}$ could be derived from the circulation. As parabiosis experiments are forbidden for ethical reasons in Australia, we investigated whether $\mathrm{ZsGreen}^{+}$cells were detectable in the circulation of $\operatorname{Prrx}^{\mathrm{ZsG}}$ mice 1, 2, 3 and 7 days following $\mathrm{SCl}$ and CDTX-mediated muscle injury (Fig. 4b, c). Flow cytometry of blood nucleated cells showed that there was a ZsGreen ${ }^{\text {low }}$ population that mostly included $\mathrm{CD}_{4} 5^{+} \mathrm{CD} 11 \mathrm{~b}^{+} \mathrm{F} 4 / 80^{+}$monocytes and $\mathrm{CD}_{4} 5^{+} \mathrm{CD} 11 \mathrm{~b}^{+} \mathrm{F} 4 / 80^{-}$populations (Fig. 4C), but the intensity of ZsGreen fluorescence in these phagocytes was two full $\log _{10}$ units lower than the ZsGreen fluorescence intensity of FAPs in the 
a
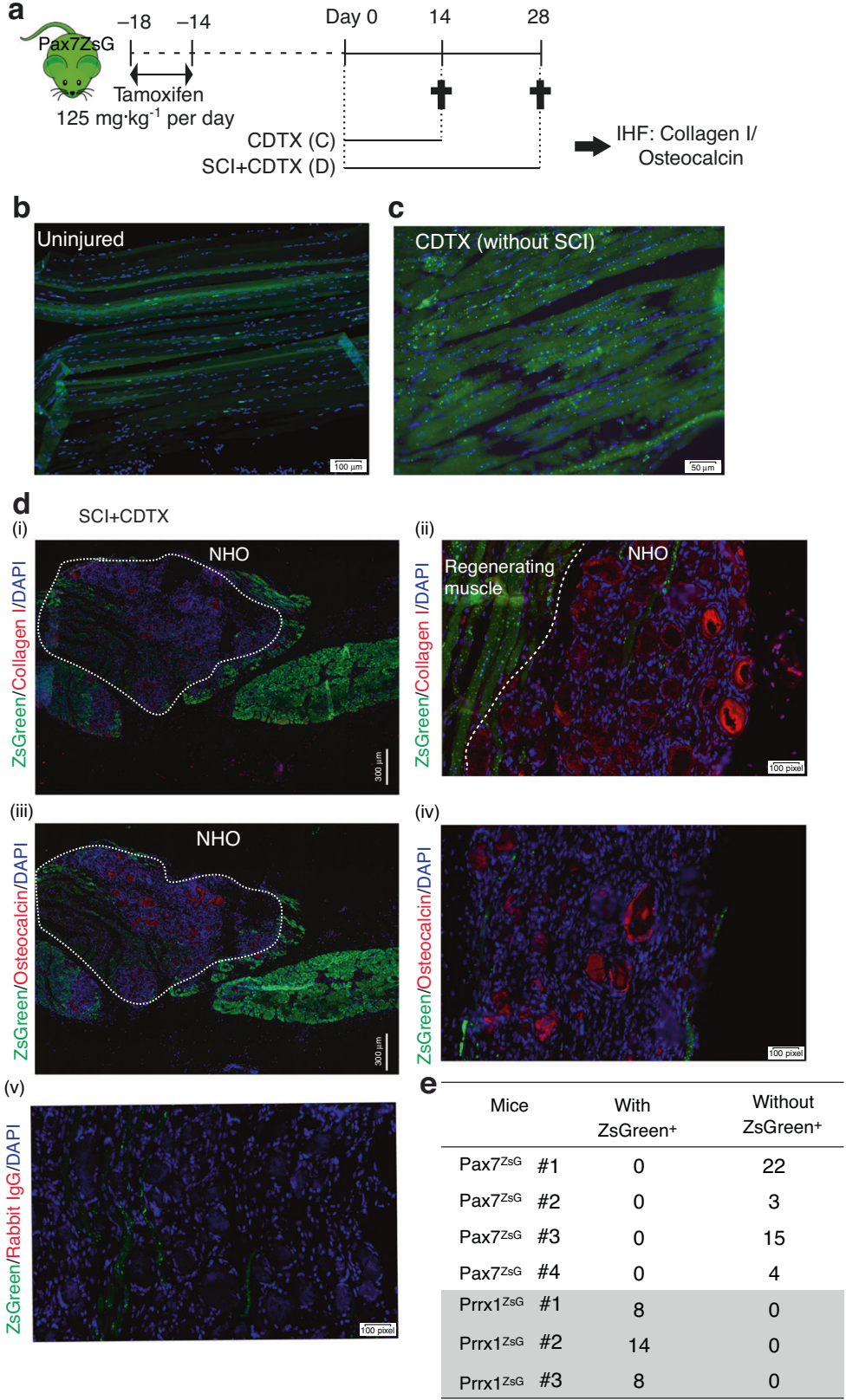

Fig. 2 NHOs are not derived from Pax7 expressing SCs. a ZsGreen expression in Pax $7^{\mathrm{ZsG}}$ mice was induced by tamoxifen treatment for 4 days. Two weeks after tamoxifen treatment, the mice received an intramuscular injection of CDTX with or without SCI. Muscle samples were harvested 14 or 28 days post-injury. Representative IHF images illustrating the distribution of ZsGreen ${ }^{+}$SC-derived cells in (b) uninjured muscle and (c) regenerated injured muscle 14 days post-CDTX injection in the Pax $7^{\mathrm{ZsG}}$ mice without SCI $(n=3$ mice/group). Scales bars: (b) $100 \mu \mathrm{m}$, (c) $50 \mu \mathrm{m}$. d Representative images from the Pax $7^{\mathrm{ZsG}}$ mice with SCl and CDTX-mediated muscle injury 28 days post-surgery. i IHF staining illustrating that ZsGreen ${ }^{+}$cells are present among areas of regenerating muscle and largely absent from areas of NHO development. White dashed lines indicate the boundary between regenerating muscle and fibrotic area containing NHOs stained red (i-ii) for collagen I and (iii-iv) osteocalcin. Nuclei were stained by DAPI staining (blue). A negative control was performed using rabbit isotype lgG (iv). Scale bars: (d) (i, iii) $300 \mu \mathrm{m}$, (ii, iv, v) $50 \mu \mathrm{m}$. e Number of osteocalcin ${ }^{+}$NHOs intercalated with ZsGreen ${ }^{+}$cells or without ZsGreen ${ }^{+}$cells in both Pax $7^{Z s G}(n=4$ mice, total 44 osteocalcin ${ }^{+}$NHOs counted) and Prrx ${ }^{\mathrm{ZsG}}$ mice $\left(n=3\right.$ mice, total 30 osteocalcin $^{+}$NHO counted). Statistical differences were determined using Fisher's exact test $\left(P<10^{-4}\right)$

muscle (Fig. 4d). Therefore, it is likely that the low ZsGreen fluorescence of blood monocytes and granulocytes is due to phagocytosis of ZsGreen (possibly packaged in extracellular vesicles ${ }^{46,47}$ ) produced by Prrx1-expressing mesenchymal progenitor cells and their progenies. Importantly, despite analyzing over $10^{6}$ blood leukocytes per mouse, we could not detect any circulating $\mathrm{CD}_{4} 5^{-} \mathrm{Lin}^{-} \mathrm{CD} 31^{-} \mathrm{Sca} 1^{+}$mesenchymal progenitor cells or cells with ZsGreen fluorescence intensity as high as FAPs in the muscle of the $\operatorname{Prrx} 1^{\mathrm{ZsG}}$ mice (Fig. 4b, d). As another potential source of "mobilized" mesenchymal cells is the bone marrow, we transplanted 90000 stromal cells enriched from the bone marrow of the Prrx ${ }^{2 \mathrm{zG}}$ mice by magnetic activated cell depletion of CD45 ${ }^{+}$ leukocytes and Ter $119^{+}$erythroid cells using the EasySep mouse stromal cell enrichment kit (Stem Cell Technologies). Following this enrichment step, $11.7 \%$ of these bone marrow stromal cells were $\mathrm{ZsG}^{\text {bright }}$ with the classic CD45 ${ }^{-} \mathrm{Lin}^{-} \mathrm{CD}_{1} 1^{-} \mathrm{Sca}^{+}$ mesenchymal progenitor cell phenotype. These cells were transplanted i.v. into three $\mathrm{C} 57 \mathrm{BL} / 6$ recipients $24 \mathrm{~h}$ post-SCI and 


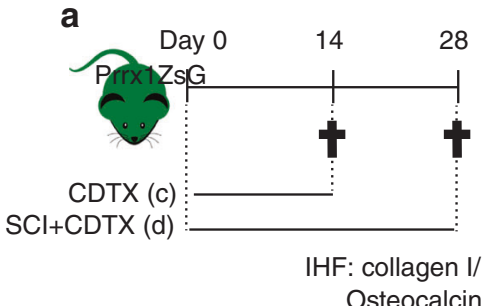

d

(i)

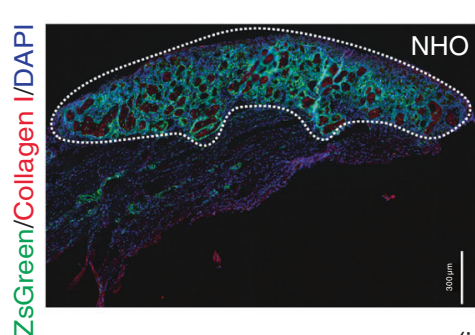

(iv)

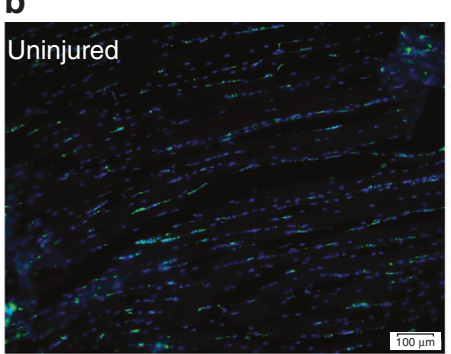

C
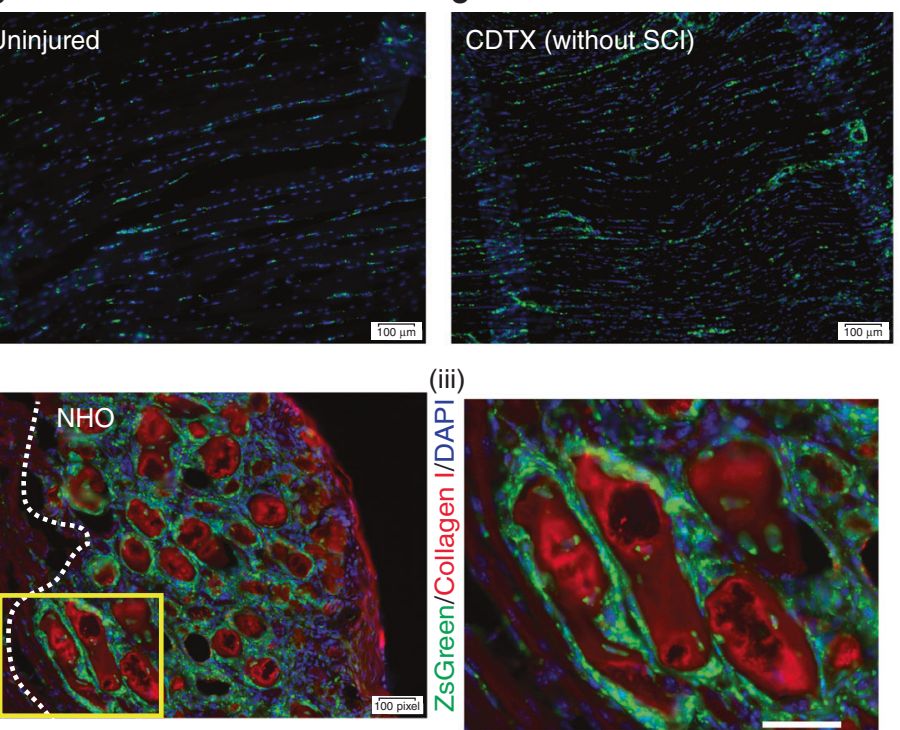

(v)

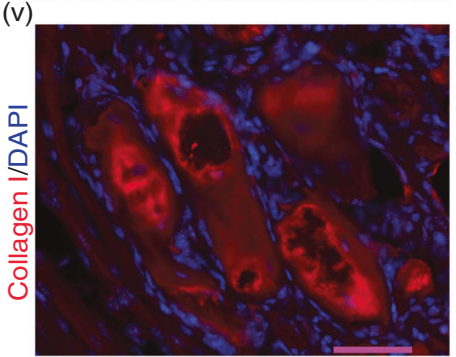

(viii)

(vi)

(vii)
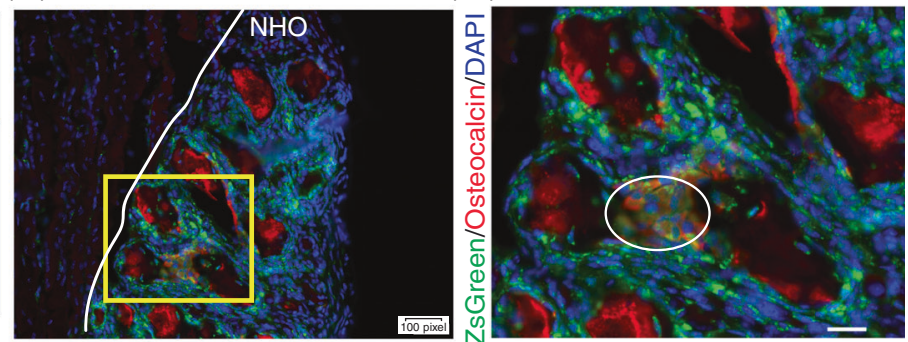

(ix)

(x)
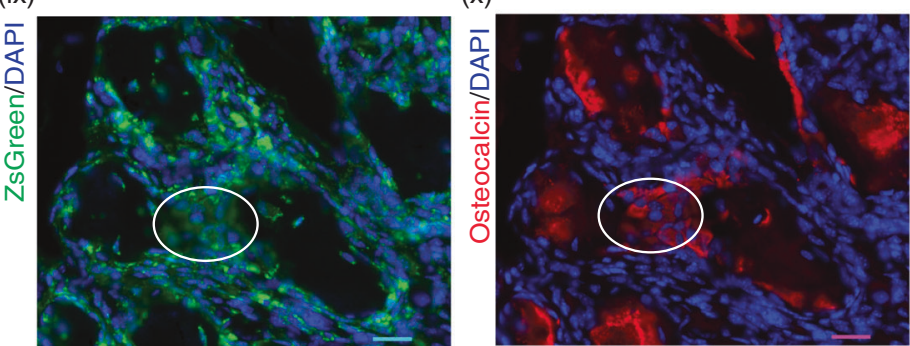

Fig. 3 NHOs are derived from Prrx 1 expressing FAPs. a Prrx $1^{Z \mathrm{sG}}$ mice received an intramuscular injection of CDTX with or without SCl, and muscle samples were harvested at the indicated time points and processed for IHF. Representative images illustrating the distribution of ZsGreen ${ }^{+}$FAPderived cells in (b) uninjured muscle and c regenerated injured muscle 14 days post-CDTX injection in the $\operatorname{Prrx} 1^{\mathrm{ZsG}}$ mice without SCl $(n=3$ mice/ group). d Representative images from the Prrx $1^{\mathrm{ZsG}}$ mice with $\mathrm{SCl}$ and CDTX-mediated muscle injury 28 days post-surgery: IHF illustrating the colocalization of ZsGreen ${ }^{+}$FAP-derived cells with (i-v) collagen $\mathrm{I}^{+}$matrix (red) or (vi-x) osteocalcin ${ }^{+}$osteoblasts (red). (iii-v) are enlarged images of the yellow box in (ii), whereas (viii-x) are enlarged images of the yellow box in (vii). The white dashed line indicates the boundary between regenerating muscle and the fibrotic area containing NHOs. Nuclei stained in DAPI (blue). White circles indicate osteocalcin ${ }^{+}$osteoblasts that also express ZsGreen. Scale bars: (b, c) $100 \mu \mathrm{m}$; (d) (i) $300 \mu \mathrm{m}$ (ii, vii) $100 \mu \mathrm{m}$ (iii-v, viii-x) $50 \mu \mathrm{m}$

CDTX muscle injury of the recipients. Muscles were analyzed by histofluorescence 21 days later, and none of the CDTX-injured muscles contained any ZsGreen-positive cells (result not shown). Therefore, while we cannot completely exclude the possibility that some of the Prrx1-expressing ZsGreen ${ }^{+}$cells associated with
NHOs following $\mathrm{SCl}$ may come from the circulation, these would be extremely rare compared to the abundance of Prrx1expressing ZsGreen ${ }^{+}$FAPs already present in the muscle prior to injury. Therefore, NHOs are most likely derived from muscleresident FAPs. 
a

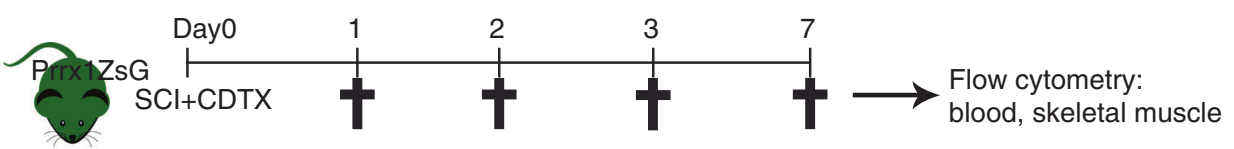

b

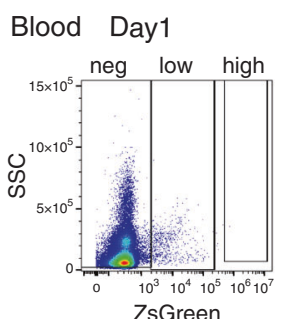

(i)

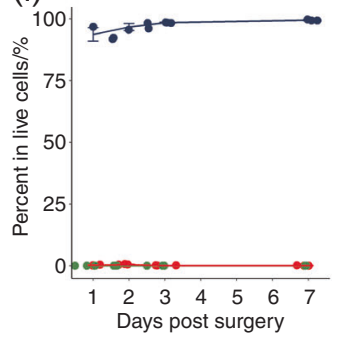

C

Blood-ZsGreen low

Day1

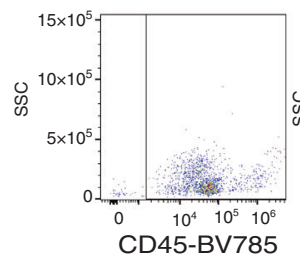

Day2
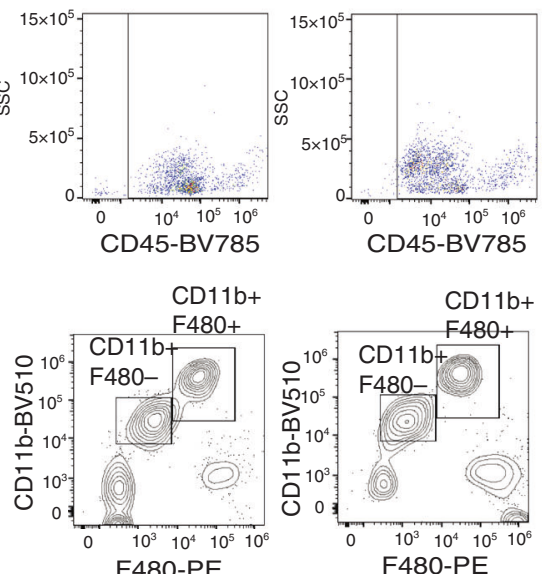

d

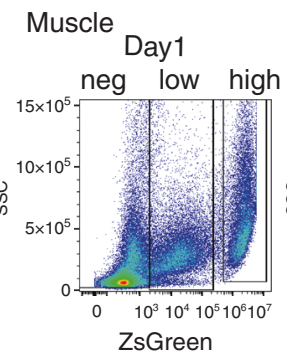

Day2

ZsGreen

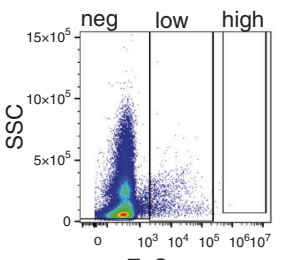

(ii)
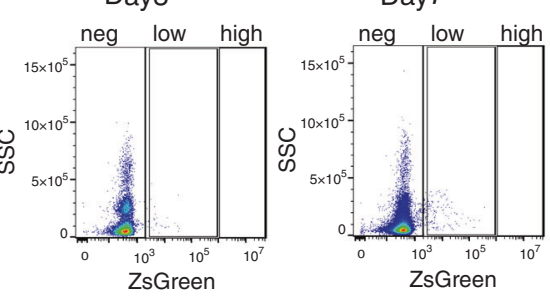

Day7

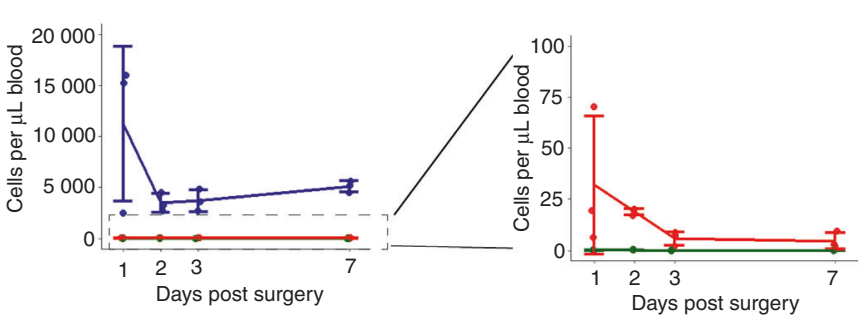

Day3

Day7
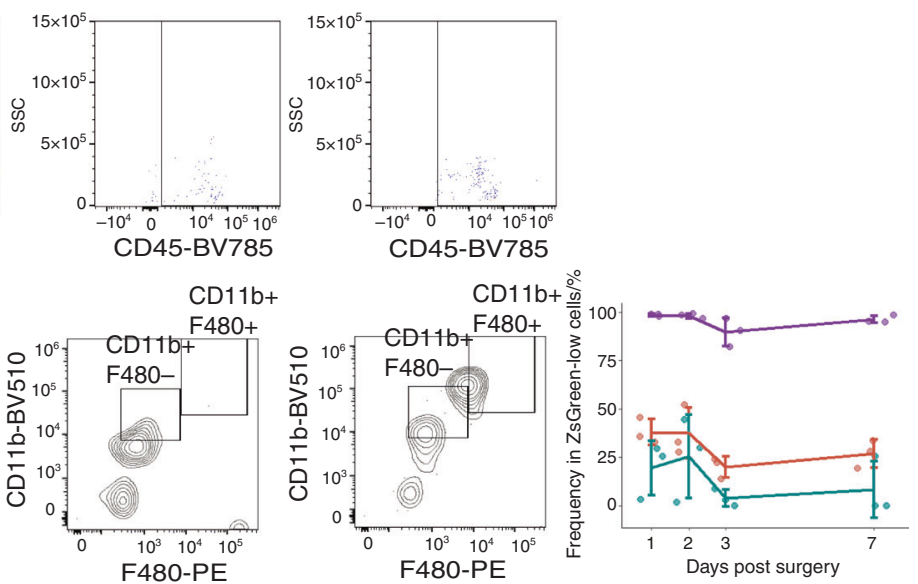

Fig. 4 Absence of ZsGreen ${ }^{\text {high }}$ mesenchymal cells in the circulation of the Prrx $1^{\mathrm{ZsG}}$ mice after SCl and muscle injury. a Prrx $1^{\mathrm{ZsG}}$ mice received $\mathrm{SCl}$ and an intramuscular injection of CDTX. Peripheral blood and skeletal muscles were collected at 1, 2, 3, and 7 days post-surgery and analyzed by flow cytometry ( $n=3$ mice/group). b FVS700 ${ }^{-}$live cells from peripheral blood were gated based on the intensity of ZsGreen fluorescence into ZsGreen negative (blue lines), low (red lines) and high groups (green lines). The frequency of these three populations is represented as (i) the frequency of live cells in blood and (ii) the number of cells per $\mu$ l blood. c The ZsGreen-low cells were further gated for expression of CD45, CD11b and F480. The frequency of CD45 leukocytes (purple line), $C D 45^{+}$CD11 b ${ }^{+}$F4/80 $0^{+}$monocytes (red line) and $\mathrm{CD} 45^{+} \mathrm{CD} 11 \mathrm{~b}^{+} \mathrm{F} 4 / 80^{-}$granulocytes (blue line) among circulating ZsG low cells was plotted. $\mathbf{d}$ Live cells from injured muscle from the same Prrx $1^{\mathrm{ZsG}}$ mice were used as a reference for ZsGreen fluorescence intensity, confirming the presence of numerous ZsGreen ${ }^{\text {high }}$ cells in muscle. ZsGreen negative (blue lines), low (red lines) and high (green lines). Each dot represents a separate mouse. Bars represent the mean \pm SD. There was no significant difference between the time points as determined by one-way ANOVA with Tukey's multiple comparison test 
Spinal cord injury causes upregulated PDGFRa expression on FAPs regardless of muscle injury

To better understand the effect of $\mathrm{SCl}$ on muscle FAPs, we followed PDGFRa expression on muscle cells. Surprisingly, PDGFRa expression was significantly upregulated on CD45 $\mathrm{Lin}^{-} \mathrm{CD}^{-} 1^{-} \mathrm{Sca}^{+} \mathrm{CD} 34^{+}$FAPs at 7 and 14 days after $\mathrm{SCl}$ in both the CDTX-injured and contralateral noninjured muscles (Fig. S5a-c). However, no expression of PDGFRa was noted on $\mathrm{CD}_{4} 5^{-} \mathrm{Lin}^{-} \mathrm{CD} 31^{-} \mathrm{Sca} 1^{-} \mathrm{CD} 34^{+} \mathrm{SCs}$ in any of the experimental conditions tested (Fig. S5d). Although it remains to be determined whether this upregulation of PDGFRa expression has a functional role in driving $\mathrm{NHO}$ development, this finding suggests that $\mathrm{SCl}$ can alter or reprogram FAP function, as shown by PDGFRa expression.

Spinal cord injury leads to reduced apoptosis and persistent proliferation of FAPs following muscle injury

Sequential induction of FAP proliferation followed by apoptosis is crucial for effective muscle repair, as either increased proliferation or decreased apoptosis can result in overexpansion of FAPs in the regenerating muscle, resulting in fibrosis. ${ }^{27}$ To examine whether the dynamics of FAP proliferation and apoptosis are perturbed during $\mathrm{NHO}$ formation, we first compared by flow cytometry the frequencies of apoptotic cells within FAP and SC populations three days post-injuries, a time point at which FAP apoptosis peaks in the regenerating muscle ${ }^{27}$ (Fig. 5a). We stained muscle cell suspensions with annexin $\mathrm{V}$ (AnnV) to detect the early stage of apoptosis together with nonmembrane permeable DNA dye 7-amino-actinomycin D (7AAD) to identify live cells $\left(A n n V^{-} 7 A A D^{-}\right)$, apoptotic cells $\left(A n n V^{+} 7 A A D^{-}\right)$and postapoptotic dead cells $\left(A n n V^{+} 7 A A^{+}\right)$. Within the $\mathrm{Lin}^{-} \mathrm{CD}_{4} 5^{-} \mathrm{CD} 31^{-} \mathrm{Sca}^{+} \mathrm{CD} 34^{+} \mathrm{ITGA7}^{-} \mathrm{FAP}$ population, muscle injury alone (sham + CDTX) led to a $17 \%$ reduction in live FAPs and a 3.2 -fold increase in apoptotic FAP frequency compared to that of naïve muscle, as previously reported $^{27}$ [Fig. 5a(i)]. However, in mice that had undergone $\mathrm{SCl}$ together with muscle injury, the frequencies of live and apoptotic FAPs were reversed and similar to those found in naïve mice. With respect to the $\mathrm{Lin}^{-} \mathrm{CD} 45^{-} \mathrm{CD} 31^{-} \mathrm{Sca} 1^{-} \mathrm{CD} 34^{+}$ ITGA7 ${ }^{+}$SC population, CDTX injury led to an $81 \%$ reduction in live SCs and a 2.6-2.7-fold increase in dead SCs regardless of the presence or absence of $\mathrm{SCl}$ [Fig. $5 \mathrm{a}$ (ii)].

We next measured muscle progenitor proliferation by in vivo 5-bromo-2'-deoxyuridine (BrdU) incorporation 14 days post surgeries. To ensure sufficient incorporation of BrdU into newly synthesized DNA during cell proliferation, we treated the mice with BrdU two days prior to tissue harvest. The percentage of proliferative $\mathrm{BrdU}^{+}$FAPs was 4.08 -fold higher in the $\mathrm{SCl}+\mathrm{CDTX}$ group than in the sham+CDTX group [Fig. $5 b(i)$ ], while there was no significant difference in the proliferation of SCs [Fig. 5b (ii)]. These results confirm that $\mathrm{SCl}$ deregulates the coordinated proliferation and apoptosis of FAPs in injured muscles.

Human PDGFRa ${ }^{+}$cells from muscles surrounding NHOs support both in vitro and in vivo bone formation

To validate the involvement of muscle-resident mesenchymal cells in human $\mathrm{NHO}$ pathology, we collected surgical residues of NHOs after resection surgery in twelve patients with $\mathrm{SCl}, \mathrm{TBI}$ and stroke. Cells were isolated from the muscle tissue surrounding the resected NHOs using mechanical dissociation and enzymatic digestion and expanded in culture. PDGFRa ${ }^{+}$ and $\mathrm{CD}_{56}{ }^{+}$cells were then isolated by fluorescence-activated cell sorting (Fig. 6a). The PDGFRa ${ }^{+}$population displayed a classical mesenchymal phenotype: $\mathrm{CD} 31^{-} \mathrm{CD}^{-} 5^{-} \mathrm{CD}^{+} 3^{+}$ $\mathrm{CD}^{+} 0^{+} \mathrm{CD}_{105^{+}}$[Fig. 6b(i)]. Interestingly, PDGFRa ${ }^{+}$cells showed heterogeneous expression of CD34, a common marker of hematopoietic and angiogenic progenitor cells [from $2 \%$ to 46.1\%; Fig. 6b(ii)]. As previously described, ${ }^{48} \mathrm{CD} 56^{+}$cells were
$\mathrm{CD}^{+}{ }^{+} \mathrm{CD} 90^{+} \mathrm{CD}_{105^{+}}[$Fig. $6 \mathrm{~b}(\mathrm{ii})]$ and expressed the myogenic regulatory transcription factors MYF5 and MYOD1 [Fig. 6b(iii)], whereas sorted PDGFRa ${ }^{+}$cells did not.

In vitro osteogenic differentiation assays showed that $\mathrm{PDGFRa}^{+}$cells exhibited a higher osteoblastic differentiation capacity than $\mathrm{CD}^{+} 6^{+}$cells (Fig. $6 \mathrm{c}$ ), and osteogenic differentiation was enhanced by the addition of $100 \mathrm{ng} \cdot \mathrm{mL}^{-1}$ recombinant human OSM (Fig. 6c), a key inflammatory mediator of $\mathrm{NHO}$ formation, as we previously reported. ${ }^{21}$

We then investigated whether cells sorted from muscles surrounding human $\mathrm{NHO}$ were able to support in vivo heterotopic bone formation in immunodeficient mice. PDGFRa ${ }^{+}$and $\mathrm{CD}^{+} 6^{+}$cells were independently seeded into plasma-clotted hydroxyapatite/calcium phosphate scaffolds and implanted subcutaneously into the backs of nude mice (Fig. 7a). Unseeded plasma-clotted scaffolds were used as a negative control, and BM-derived mesenchymal stromal cell (BM-MSC)-seeded plasmaclotted scaffolds were used as positive controls. Fifteen weeks after implantation, scaffolds were collected for histological analysis. As expected, no bone tissue was observed in the control plasma group [Fig. S6a(i)], while all BM-MSC-seeded implants exhibited bone matrix and hematopoietic foci, as detected by hematoxylin, eosin and safranin staining (HES) [Fig. S6a(ii)]. Six of 11 implants (54.5\%) with $\mathrm{NHO}$ muscle PDGFRa ${ }^{+}$ cells showed mature bone matrix containing osteocytes together with a hematopoietic marrow, demonstrating the formation of ectopic bone with functional hematopoietic BM [Fig. 7b, c(i)], as evidenced by the presence of numerous mature megakaryocytes (Fig. S6b). In contrast, only $12.5 \%$ of scaffolds seeded with CD56 ${ }^{+}$ cells contained bone matrix deposition alone, and $12.5 \%$ showed both bone matrix development and hematopoietic colonization [Fig. 7b, c(i)], suggesting a much higher osteogenic potential of $\mathrm{PDGFRa}^{+}$mesenchymal cells derived from human muscle surrounding NHOs. To analyze the origin of bone-forming cells in these implants, we investigated the expression of humanspecific lamin A/C by immunohistochemistry. Figure 7c(ii) highlights that very few human cells were observed within $\mathrm{CD} 56^{+}$cell seeded scaffolds, whereas $\mathrm{PDGFRa}^{+}$cell seeded implants exhibited numerous human lamin $\mathrm{A} / \mathrm{C}^{+}$osteocytes within the bone matrix [Fig. 7c(ii)], demonstrating that human PDGFRa ${ }^{+}$ cells actively participate in the formation of heterotopic bone. Of note, no human cells were detected within hematopoietic foci, confirming that hematopoietic cells that colonized these heterotopic bone formations were of murine origin (Fig. S6b). Finally, PDGFRa ${ }^{+}$cell implants exhibited numerous osterix ${ }^{+}$ osteoblasts; most of them were located near hydroxyapatite particles and within the bone matrix (Fig. 7d). Thus, mesenchymal PDGFRa ${ }^{+}$cells isolated from muscles surrounding human $\mathrm{NHOs}$ have a substantially higher capacity to support mature hemogenic bone formation than myogenic $\mathrm{CD} 56^{+}$cells. These data are concordant with the hypothesis that muscle-resident $\mathrm{PDGFRa}^{+}$cells are key actors in the onset of NHOs in both humans and mice.

\section{DISCUSSION}

Although NHOs develop mostly in peri-articular muscles in humans, ${ }^{1,2}$ their cellular origin remains unclear. Using $P a x 7^{\mathrm{ZsG}}$ mice that specifically trace muscle SCs and their myogenic progenies, we clearly demonstrate that $\mathrm{NHOs}$ developing after $\mathrm{SCl}$ in injured muscles in mice are not derived from muscle SCs. We also reveal that $\mathrm{NHOs}$ only develop in areas of the injured muscle where SCs fail to regenerate myofibers, with $\mathrm{NHOs}$ only found in areas where ZsGreen-labeled SC-derived myocytes or myofibers are completely absent. Likewise, $\mathrm{CD}^{+} 6^{+}$muscle progenitors sorted from the muscles surrounding $\mathrm{NHOs}$ from $\mathrm{SCl}$ patients do not effectively generate ectopic bones when transplanted into permissive immunodeficient mice. 
a

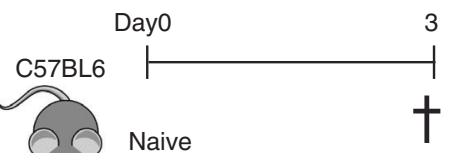

SCl+CDTX Flow cytometry: Annexin V

Sham+CDTX

(i) $\mathrm{Sca} 1+\mathrm{CD} 34+\mathrm{FAPs}$
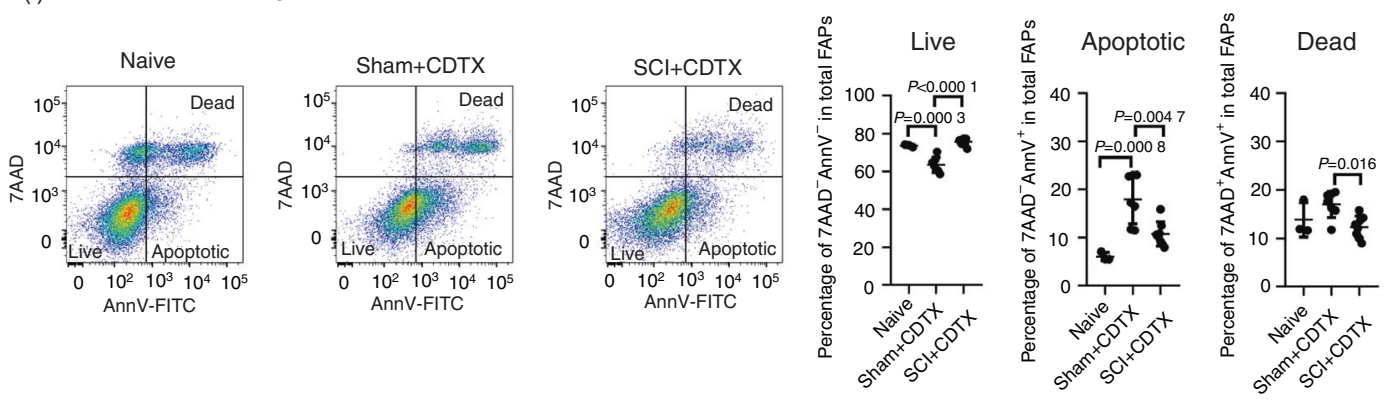

(ii) Sca1- $\mathrm{CD} 34+\mathrm{SCs}$
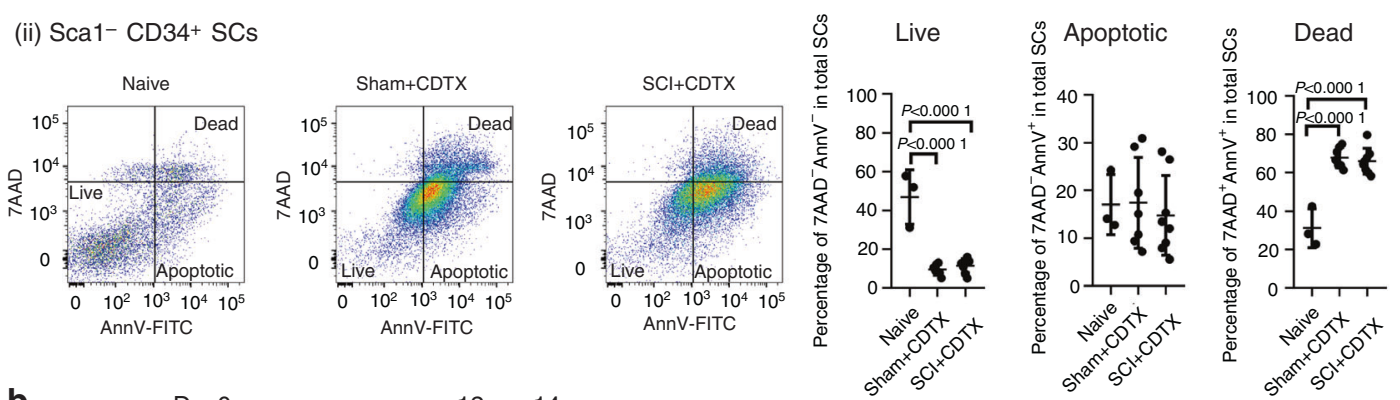

b

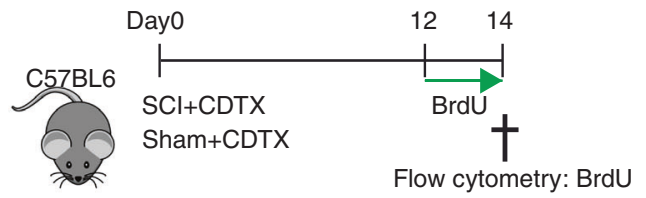

(i) $\mathrm{Sca} 1+\mathrm{CD} 34+$ FAPs
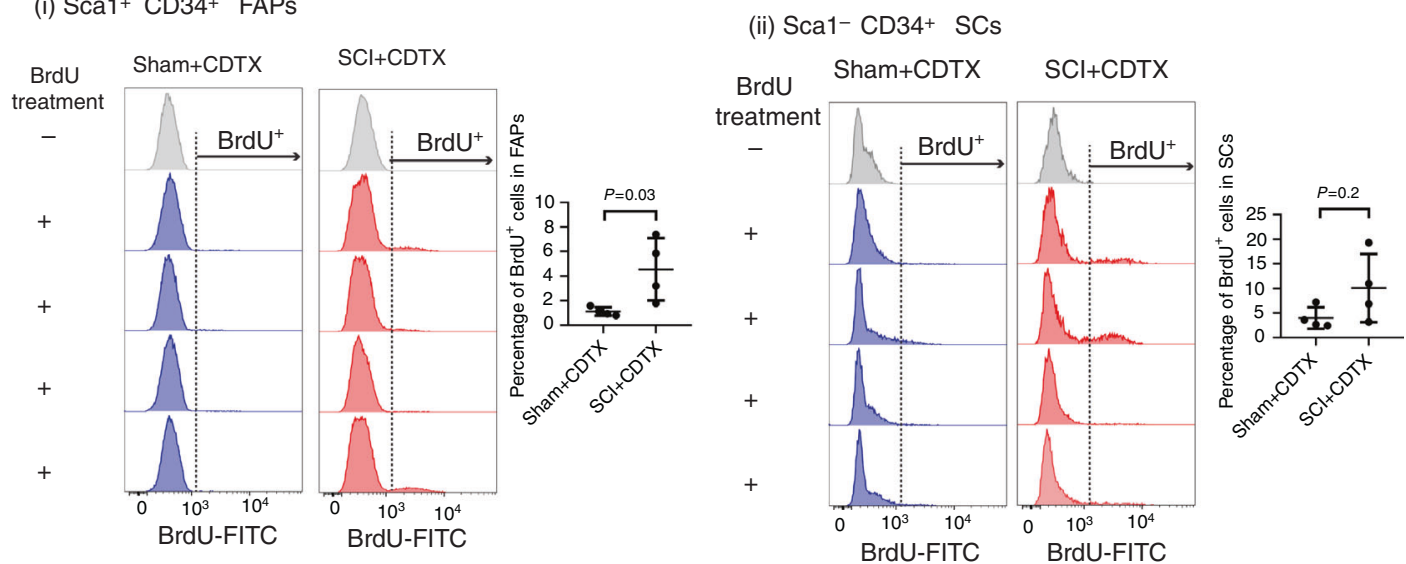

Fig. $5 \mathrm{SCl}$ leads to decreased apoptosis and persistent proliferation of FAPs in injured muscles. a Naïve C57BL/6 mice underwent SCl or sham surgery plus intramuscular injection of CDTX. Muscle cells were isolated 3 days later. Apoptotic cells were subsequently analyzed by Annexin $V$ (AnnV) and 7-amino-actinomycin D (7AAD) staining by flow cytometry. (i) CD45 Lin $^{-}$CD31- Sca ${ }^{+} \mathrm{CD}^{-} 4^{+}$ITGA7 ${ }^{-}$FAPs and (ii) CD45 Lin $^{-}$ $\mathrm{CD}^{-} 1^{-} \mathrm{Sca}^{-} \mathrm{CD}^{-} 4^{+} \mathrm{ITGA}^{+} \mathrm{SC}$ were gated. AnnV and 7AAD staining further distinguished cells as live $\left(7 \mathrm{AAD}{ }^{-}\right.$AnnV ${ }^{-}$), apoptotic $\left(7 A A D^{-} A_{n n V}+\right)$ and postapoptotic dead $\left(7 A A D^{+} A n n V^{+}\right)$in both FAP and SC populations. The percentages of live, apoptotic and dead cells in the total FAP or SC populations are presented as the mean $\pm \mathrm{SD}(n=3,7$, and 8 in naïve, sham $+\mathrm{CDTX}$, and $\mathrm{SCl}+\mathrm{CDTX}$, respectively). Each dot represents a separate mouse. Significance was calculated by one-way ANOVA with Tukey's multiple comparison test. b C57BL/6 mice underwent $\mathrm{SCl}$ or sham surgery plus intramuscular injection of CDTX. Mice were given drinking water containing BrdU together with BrdU i.p. injection (twice daily) from day 12 to 14 . One SCI + CDTX and 1 sham+CDTX mouse were not treated with BrdU and used as a negative control for anti-BrdU staining. On day 14, muscle cells were isolated, and BrdU staining was analyzed in CD45 $\mathrm{Lin}^{-} \mathrm{CD} 31^{-} \mathrm{Sca} 1^{+} \mathrm{CD} 34^{+} \mathrm{ITGA}^{-}$ FAPs and CD45 $\mathrm{Lin}^{-} \mathrm{CD} 31^{-} \mathrm{Sca}^{-} \mathrm{CD}^{+} 4^{+}$ITGA7 ${ }^{+} \mathrm{SCs}$ by flow cytometry. The percentage of BrdU ${ }^{+}$cells in the total FAP or SC population is presented as the mean \pm SD. Each dot represents a separate mouse. Significance was calculated by a two-sided Mann-Whitney test 

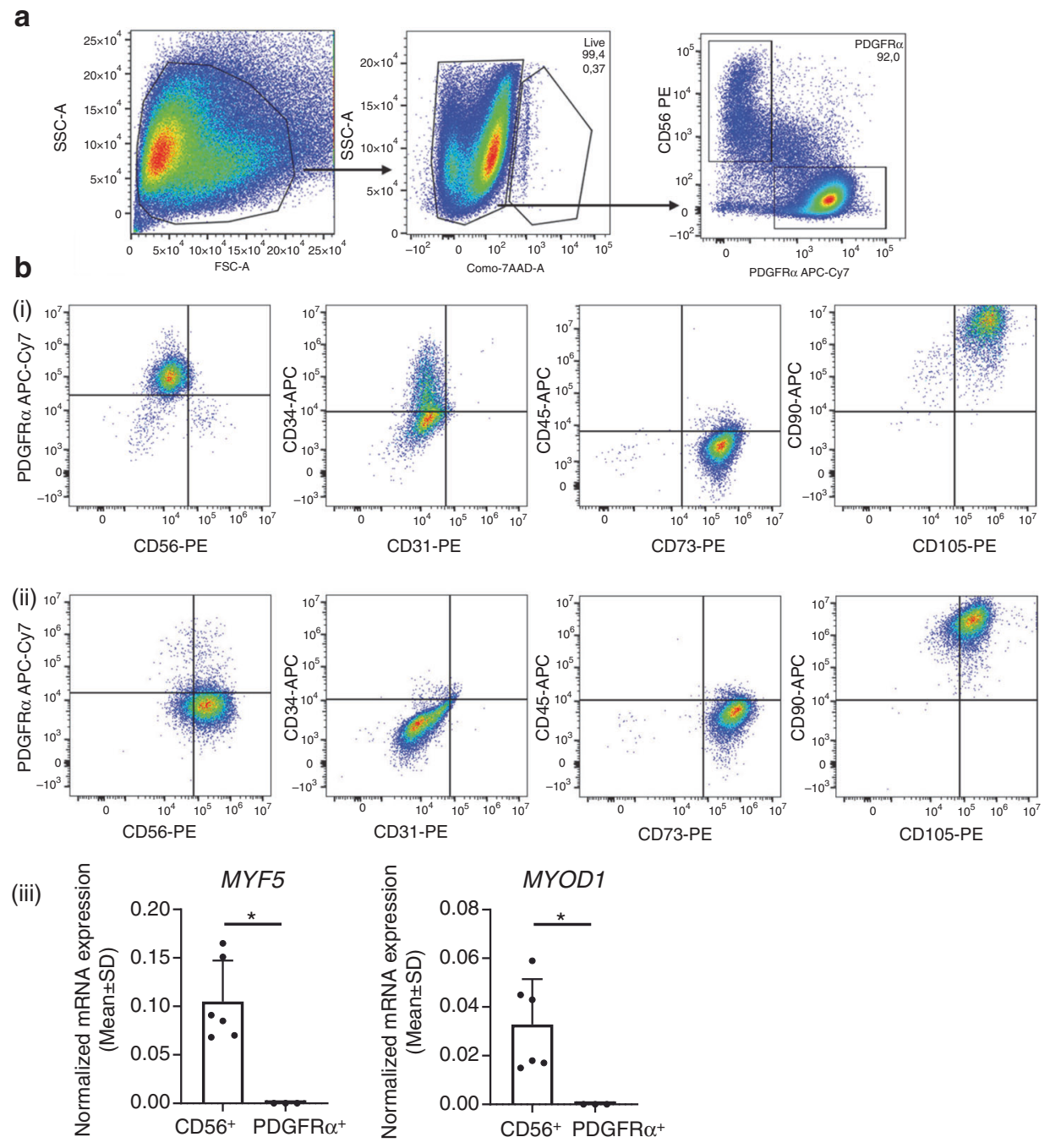

C
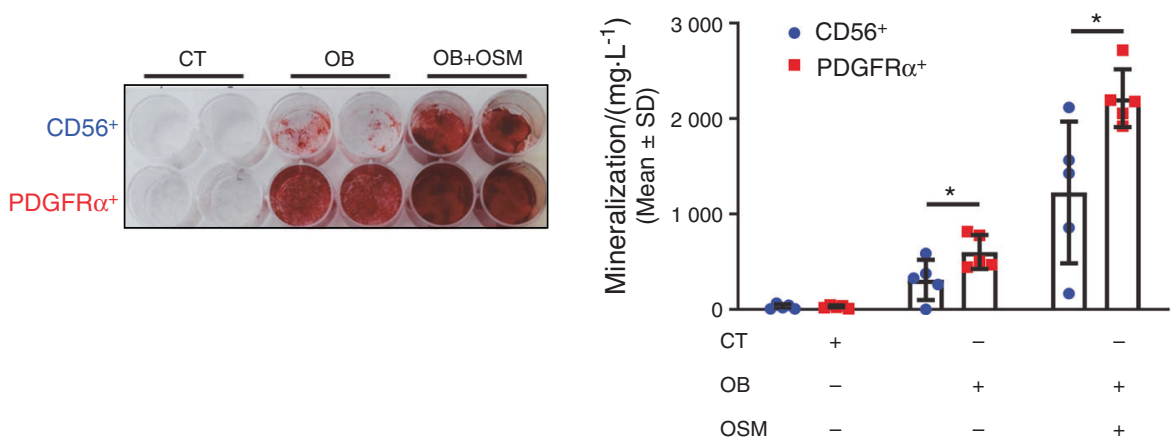

Fig. 6 Human PDGFR $\alpha^{+}$cells isolated from muscles surrounding NHOs support in vitro bone formation. a Flow cytometry gating strategy of PDGFR $\alpha^{+}$and $\mathrm{CD}_{56}{ }^{+}$cell subpopulations isolated from muscle surrounding NHOs. b Representative surface marker characterization by flow cytometry: CD56, PDGFR $\alpha$, CD31, CD34, CD45, CD73, CD90, and CD105, (i) CD56 ${ }^{+}$population, (ii) PDGFR $\alpha^{+}$population, (iii) Normalized mRNA expression of MYF5 and MYOD1 by qRT-PCR expressed as the mean \pm SD (CD56 ${ }^{+} n=6$; PDGFR $\left.\alpha^{+} n=3\right)$. c In vitro osteoblastic differentiation assay seeded with $\mathrm{CD}_{5} 6^{+}$or PDGFR $\alpha^{+}$cells isolated from muscles surrounding human NHOs. (i) All cells were cultured in control medium (CT) or osteogenic medium alone (OB) or were supplemented with human OSM (100 $\left.\mathrm{ng} \cdot \mathrm{mL}^{-1}\right)(\mathrm{OB}+$ OSM) for 14 days followed by Alizarin Red S staining. c(ii) Quantification of calcium mineralization expressed as the mean \pm SD $(n=5)$. ${ }^{*} P<0.05$, two-sided nonparametric Mann-Whitney U test

Therefore, although NHOs almost always develop in muscles, they are not the product of muscle SC transdifferentiation. In contrast, we found focal accumulation and osteoblastic differentiation of the Prrx1-expressing PDGFRa ${ }^{+}$mesenchymal progenitor cells among areas of $\mathrm{NHO}$ development in the Prrx $1^{Z s G}$ mice. This finding suggests that $\mathrm{SCl}$ perturbs normal or early proliferation followed by apoptosis of FAPs in the injured muscle with continued proliferation and absence of apoptosis of FAPs. High magnification of $\mathrm{NHO}$ sections in the Prrx $1^{\mathrm{ZsG}}$ mice also revealed that osteocalcin ${ }^{+}$osteoblasts and osteogenic progenitors contained in the developing NHOs were labeled by ZsGreen and thus derived from the Prrx1-expressing mesenchymal 
a

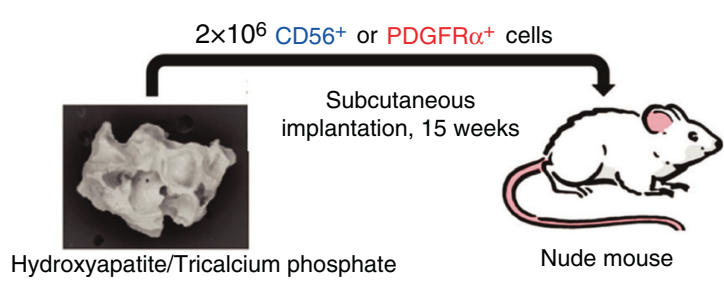

b

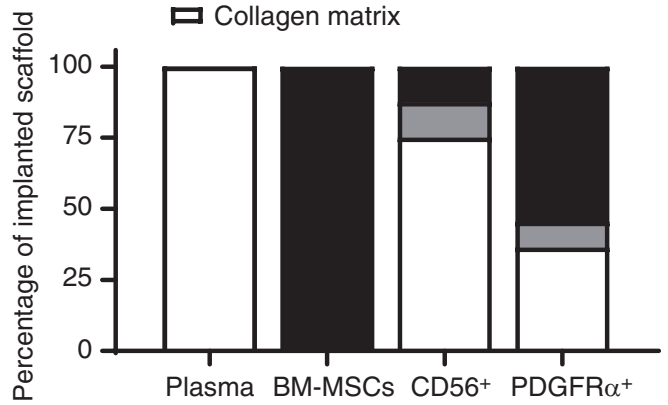

C

(ii)

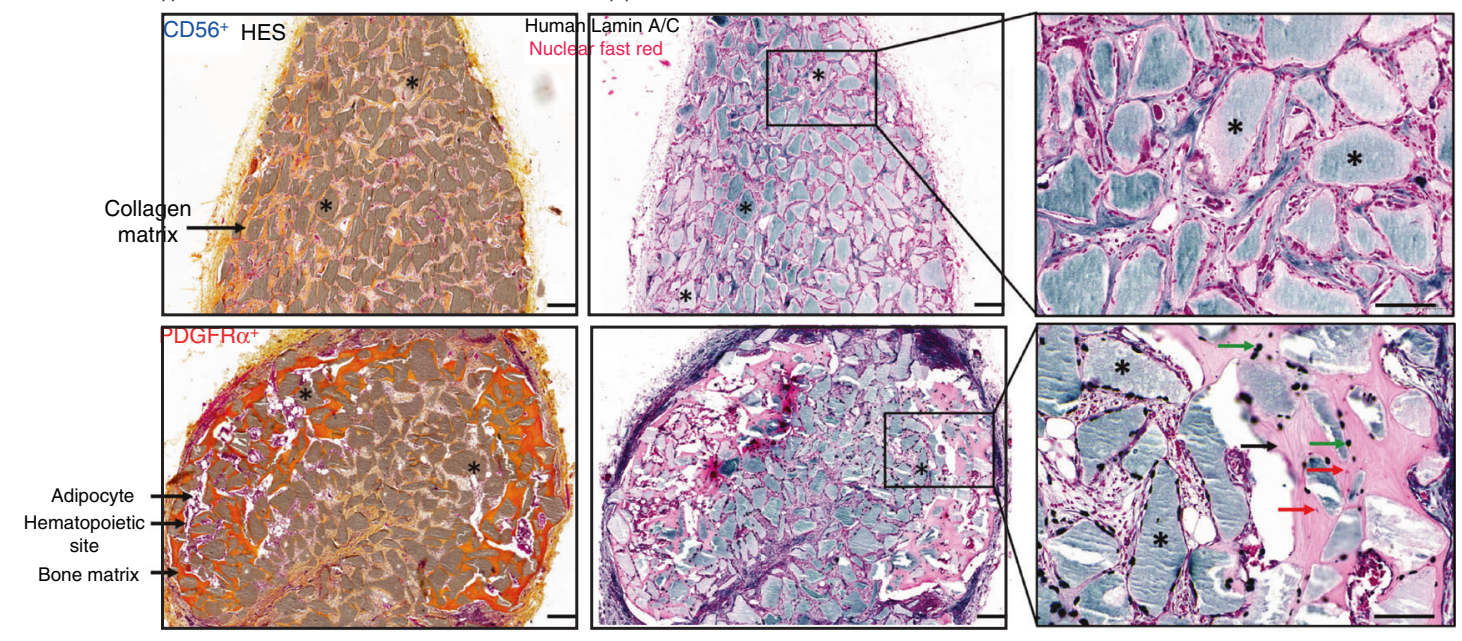

d

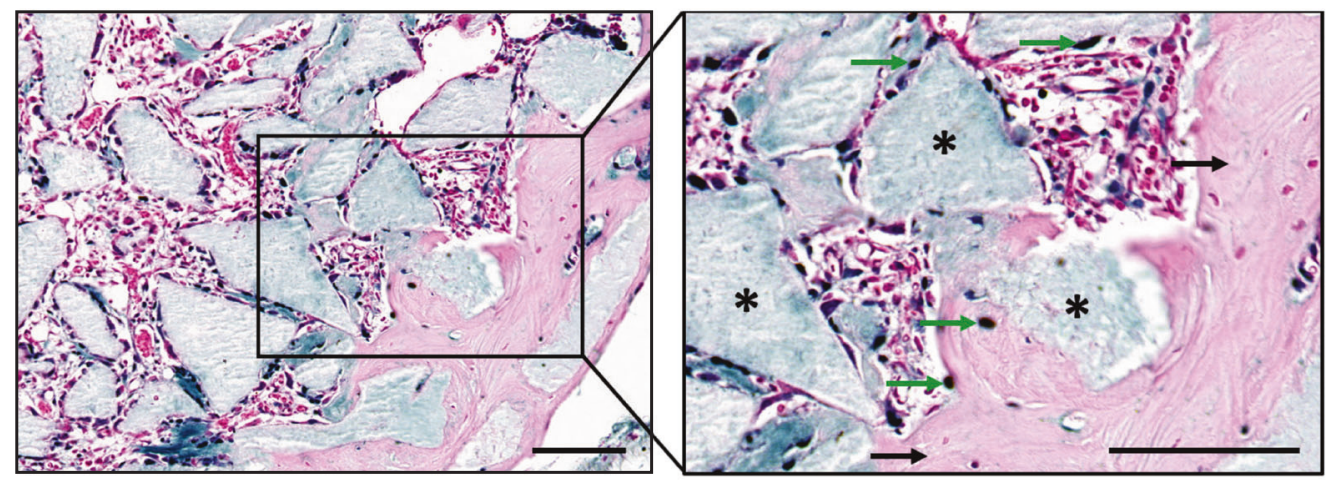

Fig. 7 Human PDGFR $\alpha^{+}$cells isolated from muscles surrounding NHO support in vivo bone formation. a Schematic representation of the in vivo osteogenic assay. Hydroxyapatite/calcium phosphate plasma scaffolds were seeded either with $2 \times 10^{6} \mathrm{CD} 56^{+}$cells, $2 \times 10^{6}$ PDGFR $\alpha^{+}$cells sorted from muscles surrounding NHOs, $2 \times 10^{6}$ human BM-MSCs or without cells ("plasma" negative control) and subcutaneously implanted in the backs of nude mice for 15 weeks. b Percentage of scaffolds containing either collagen matrix alone, bone matrix alone, or bone matrix associated with hematopoietic colonization. Human plasma ( $n=4$ donors), BM-MSCs ( $n=6$ donors), CD56 ${ }^{+}$cells ( $n=8 ; 4$ donors, 2 implants/donor) and PDGFR $\alpha^{+}$ cells ( $n=11 ; 6$ donors, 2 implants/donor for 5 donors and 1 implant for one donor). c(i) Representative images of hematoxylin-eosin-safranin (HES) staining of $\mathrm{CD}^{+} 6^{+}$and PDGFR $\alpha^{+}$cell-seeded implant sections. Nuclei are stained purple, cell cytoplasm is stained pink, and collagen fibers are stained orange. *: hydroxyapatite. Magnification 10X; scale bar $=100 \mu \mathrm{m}$. c(ii) Specific human Lamin A/C staining of representative CD56 ${ }^{+}$and PDGFR $\alpha^{+}$cell-seeded implant sections. *: hydroxyapatite scaffold; black arrows: bone matrix; green arrow: human osteocytes; red arrows: mouse osteocytes. Magnification $\times 10$ and $\times 20$; scale bar $=100 \mu \mathrm{m}$. d Osterix/SP7 staining of a representative PDGFR $\alpha^{+}$cell-seeded implant section. *: hydroxyapatite scaffold; black arrows: bone matrix; green arrows: osterix ${ }^{+}$osteoblasts. Magnification $\times 20$ and $\times 40 ;$ scale bar $=100 \mu m$

progenitor cells that shared the same antigenic profile as muscle FAPs. Likewise, over half of PDGFRa ${ }^{+}$mesenchymal progenitors sorted from the muscles surrounding $\mathrm{NHO}$ from $\mathrm{SCl}$ patients effectively formed ectopic bones when transplanted into permissive immunodeficient mice. One of 8 preparations of $\mathrm{CD}^{+} 6^{+}$muscle progenitor cells from these $\mathrm{NHO}$ biopsies could form ectopic bones with hematopoietic marrow when implanted in mice. Although it remains unclear whether this was caused by contaminating mesenchymal cells in the sorted population, our results suggest that in both mice and humans, NHOs are derived from mesenchymal progenitor cells and not from myogenic progenitor cells such as SCs. 
The Pax7Cre ${ }^{\text {ERT2 }}$ model we employed has been used by many groups to specifically target and trace SCs in muscles following injury, ${ }^{39,49,50}$ which validates our use of $\mathrm{Pax} 7^{\mathrm{ZsG}}$ in our study. While there is no marker that is exclusively restricted to muscle FAPs, it is well known that Prrx1Cre (often called Prx1-Cre) targets and labels mesenchymal stromal cells in the developing limb buds as well their progenies in adults. ${ }^{40}$ Prrx $1 \mathrm{Cre}$ mice have been successfully used to target mesenchymal progenitor cells in adult bone marrow ${ }^{51}$ and mesenchymal progenitor cellderived chondroprogenitors, osteoprogenitors in bones, ligaments, tendons ${ }^{52}$ and adipocytes, ${ }^{53}$ all of which are of mesenchymal origin. ${ }^{54}$ Therefore, the mesenchymal specificity of the Prrx1Cre strain is well established. Herein, we show that in skeletal muscle, Prrx1Cre exclusively labels mesenchymal cells with the typical FAP phenotype (expressing CD34, Sca-1 and PDGFRa antigens at the cell surface but not ITGA7, which is specific to SCs in the muscle ${ }^{25}$ ) both before and after muscle injury. Furthermore, these cells are reticulated and scattered along myofibers and do not form myofibers in the regenerating muscle, consistent with the known function of FAPs in coordinating muscle repair rather than forming new myocytes. $^{25-29}$ Therefore, although Prrx1Cre targets many other mesenchymal cells in various tissues of the body, it exclusively labels FAPs in the noninjured skeletal muscle. From these considerations, we conclude that our lineage-tracing models establish that the cells of origin that form $\mathrm{NHO}$ following $\mathrm{SCl}$ are mesenchymal progenitor cells, not muscle satellite cells.

Other studies using models of FOP, ${ }^{32,34}$ calcific tendinitis and $\mathrm{HO}$ subsequent to tenectomy ${ }^{43}$ suggest that circulating mesenchymal progenitors contribute to $\mathrm{HO}$ formation. Therefore, we explored whether Prrx1-expressing cells circulate following $\mathrm{SCl}$ or muscle injury using Prrx $1^{\mathrm{ZsG}}$ mice. As parabiosis experiments are banned in Australia for ethical reasons, we instead tracked these cells by flow cytometry of the peripheral blood. No cells expressing high levels of ZsGreen or with a FAP phenotype were detected in the blood of the Prrx $1^{\mathrm{ZsG}}$ mice at multiple timepoints following $\mathrm{SCl}$ and muscle injury, whereas these $\mathrm{ZsGreen}{ }^{\text {high }}$ cells were very abundant in both naïve and injured muscles. Therefore, considering the high abundance of Prrx1-expressing FAPs in the muscle itself and their extreme rarity in the blood, it is very unlikely that $\mathrm{NHOs}$ following $\mathrm{SCl}$ are derived from circulating mesenchymal cells. Although our SCl-induced $\mathrm{NHO}$ model does not involve BMP signaling and endochondral ossification, our result is consistent with a report showing that in a model of $\mathrm{HO}$ induced by implantation of BMP-2 Matrigel, $\mathrm{HOs}$ are not derived from circulating mesenchymal progenitors but from local FAPs. ${ }^{35}$

As lineage tracing experiments are not possible in humans, we attempted to validate our results from mice with $\mathrm{NHO}$ biopsies resected from patients with $\mathrm{SCl}$ and traumatic brain injury. We isolated progenitor cell populations from skeletal muscle residues surrounding these resected NHOs. Because of the small amount of muscle tissue on the surgical residues, adherent cells were amplified before and after sorting, possibly resulting in slight phenotypic changes. We sorted $\mathrm{CD}^{+} 6^{+}$cells known as myogenic progenitor cells. ${ }^{48}$ Although they expressed CD90, CD105 and CD73 in culture, they were negative for PDGFRa and expressed the key myogenic regulatory transcription factors MYF5 and MYOD1. Conversely, PDGFRa ${ }^{+}$cells had the classical mesenchymal cell phenotype, were $\mathrm{CD}_{5} 6^{-}$and did not express the myogenic regulatory factors MYF5 or MYOD1. Therefore, human muscle $\mathrm{CD}_{56}^{+}$and $\mathrm{PDGFRa}{ }^{+}$populations correspond to Pax7- and Prrx1-expressing SCs and FAPs in mice. In our in vitro osteogenic assay, PDGFRa ${ }^{+}$cells always had a higher osteogenic potential than $\mathrm{CD}_{5} 6^{+}$muscle progenitors, especially in the presence of the proinflammatory cytokine OSM. PDGFRa ${ }^{+}$cells were also more efficient in developing ectopic bones with human-derived osteocytes and osteoblasts and hematopoietic marrow when subcutaneously implanted in a conductive biomaterial in immunodeficient mice. Our findings are consistent with a previous report that showed that although both populations displayed osteogenic potential in vitro, PDGFRa ${ }^{+}$ cells had a far superior ability to form ectopic bones when transplanted on a supportive scaffold into immunodeficient mice, as previously reported. ${ }^{55}$ Taken together, these results strongly support the mesenchymal and nonmyogenic origin of $\mathrm{NHOs}$ in patients with $\mathrm{SCl}$.

Together, our lineage-tracing experiments suggest that $\mathrm{NHO}$ development subsequent to $\mathrm{SCl}$ is a pathology of the injured muscle, where muscle regeneration is deregulated with failure of muscle SCs to regenerate myocytes. We found that after $\mathrm{SCl}$, fewer FAPs underwent apoptosis at day 3 following muscle injury, while FAPs continued to proliferate and incorporate BrdU even at days 12-14 post-injury. This finding suggests that subsequent to $\mathrm{SCl}$, extensive and uncontrolled FAP survival, proliferation, and differentiation results in the formation of extensive fibrotic areas in which osteogenic differentiation leads to heterotopic bone formation rather than muscle repair. This finding suggests that severe CNS trauma, such as $\mathrm{SCl}$, can reprogram FAPs in injured muscle, whereby the apoptotic process that occurs in proliferative FAPs to reduce their numbers back to baseline levels after muscle injury $^{26,27,29}$ is impaired in the context of SCl. As a consequence, proliferating FAPs fail to undergo apoptosis and continue to accumulate in the injured muscle, which becomes fibrotic, followed by osteogenic differentiation of these FAPs into osteoblast-like cells, leading to the development of heterotopic bone tissue within injured muscles. From this perspective, we showed that $\mathrm{SCl}$ causes the selective upregulation of PDGFRa expression at the surface of muscle FAPs independent of the muscle injury itself, with no such effect on SCs. This finding is consistent with the observation that sciatic nerve transection also upregulates PDGFRa expression in denervated hindlimb muscle, ${ }^{28}$ resulting in FAP accumulation and muscle fibrosis. ${ }^{28,56,57}$ While heterotopic ossifications were not reported in these CDTX-injured denervated hindlimbs, ${ }^{56,57}$ we have shown that in the presence of an $\mathrm{SCl}$, denervation further increases $\mathrm{NHO}$ volumes. ${ }^{58}$ Therefore, our data suggest that $\mathrm{SCl}$ reprograms FAPs in skeletal muscles, resulting in increased PDGFRa expression, reduced apoptosis and persistent proliferation in injured muscles. As PDGF and its receptors are prime survival and proliferative signals in mesenchymal cells, this may contribute to $\mathrm{NHO}$ development. This conclusion will need to be further confirmed in future work, and it will be of interest to identify which factors (neural or systemic) cause upregulation of PDGFRa expression on FAPs in response to $\mathrm{SCl}$.

In conclusion, our lineage tracing experiments in mice and xenotransplantation of human muscle cells associated with $\mathrm{NHOs}$ reveal that $\mathrm{NHO}$ is a pathology of the injured muscle in which $\mathrm{SCl}$ reprograms FAPs in the damaged muscle with fibrotic hyperproliferation and osteogenic differentiation instead of apoptosis. Importantly, there was no transdifferentiation of muscle satellite cells. These findings clarify the question of the cells of origin of $\mathrm{NHOs}$, demonstrating for the first time that severe CNS traumas can reprogram FAPs in skeletal muscles. This new knowledge may provide new therapeutic opportunities to reduce $\mathrm{NHO}$ development in victims of severe CNS traumas.

\section{MATERIALS AND METHODS}

Animal ethics and sources

All experimental procedures in mice were approved by the Health Sciences Animal Ethics Committee of The University of Queensland and followed the Australian Code of Practice for the Care and Use of Animals for Scientific Purposes. In vivo osteogenic assays in nude mice were approved by the French Institutional Animal Care and Use Committee CAPSUD/N²6 under ethics approval \#9516/ 2017040715214163. C57BL/6 mice were obtained from the Animal Resource Center (Perth, Australia). 
Lineage tracing animal models

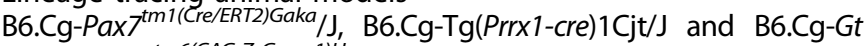
(ROSA)26Sor tm6(CAG-ZsGreen1)Hze/J mice were purchased from the

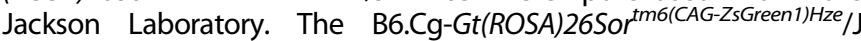
reporter strain (or ROSA26-LoxP-STOP-loxP-ZsGreen) has a CAG promoter-driven floxed STOP codon cassette ZsGreen cassette knocked into the ROSA26 gene trap locus; therefore, ZsGreen is only expressed once recombined by Cre recombinase. To specifically

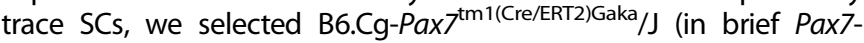
CreERT2) mice in which Cre recombinase is fused with a mutant estrogen receptor (CreERT2) fusion protein sequence that makes it tamoxifen-inducible and knocked-in together with an intraribosomal entry site downstream of the stop codon of the $P a x 7$ gene, which is specifically expressed in $\mathrm{SCs}^{39}{ }^{39 x} \mathrm{Z}^{\mathrm{ZsG}}$ mice were generated by crossing Pax7-CreERT2 with ROSA26-LoxP-STOP-loxP-ZsGreen mice (Fig. 1a). The primers and PCR conditions for genotyping are detailed in Table S2. CreERT2 nuclear translocation and subsequent ZsGreen expression by excision of the floxed STOP cassette in $P a x 7^{Z \mathrm{sG}}$ mice was induced by daily oral gavage with tamoxifen $125 \mathrm{mg} \cdot \mathrm{kg}^{-1}$ for 4 days followed by a 2-week rest prior to surgery or CDTX intramuscular injection. To trace FAPs, we selected B6.Cg-Tg(Prrx1cre) $1 \mathrm{Cjt} / \mathrm{J}$ transgenic mice (in brief Prrx1-Cre), in which Cre recombinase expression is controlled by the Prrx 1 promoter/ enhancer specifically expressed in mesenchymal stem and progenitor cells. Prrx $1^{\mathrm{ZsG}}$ mice were generated by crossing Prrx 1 -Cre males with ROSA26-LoxP-STOP-loxP-ZsGreen female mice. The genotype of Prrx1-ZsGreen mice was confirmed by PCR as recommended by the Jackson Laboratory.

Mouse model of SCl-induced $\mathrm{NHOs}$

For induced $\mathrm{NHO}$ formation, 5- to 8-week-old female mice underwent spinal cord transaction surgery $(\mathrm{SCl})$ at $\mathrm{T} 11-13$ or control sham surgery (surgical incisions were only created on skin and muscle without damaging the spinal cord) followed by an intramuscular injection (i.m.) of $0.32 \mathrm{mg} \cdot \mathrm{kg}^{-1}$ purified Naja pallida CDTX (Latoxan, France) or an equal volume of sterile phosphate buffered saline (PBS). ${ }^{20}$ Mice were euthanized by $\mathrm{CO}_{2}$ asphyxiation at the indicated time points. Hamstring muscle samples were processed for flow cytometry or histological analysis as stated below.

Flow cytometry

Single cells from hamstring muscles were isolated using a skeletal muscle dissociation kit (Miltenyi Biotech) and GentleMACS Dissociator tissue homogenizer (Miltenyi Biotec, Macquarie Park, Australia) as previously described. ${ }^{20}$ Blood samples were collected by terminal cardiac puncture 1, 2, 3 and 7 days post-surgery in heparinized tubes under anesthesia (2\%-3\% isoflurane). Red blood cells were lysed in $150 \mathrm{mmol} \cdot \mathrm{L}^{-1} \mathrm{NH}_{4} \mathrm{Cl}, 10 \mathrm{mmol} \cdot \mathrm{L}^{-1} \mathrm{NaHCO}_{3}$, and $1 \mathrm{mmol} \cdot \mathrm{L}^{-1}$ EDTA, $\mathrm{pH}=7.4$ buffer, with mixing, and the remaining cells were washed again in PBS containing $10 \%$ newborn calf serum (NCS) and $2 \mathrm{mmol} \cdot \mathrm{L}^{-1}$ EDTA prior to staining.

For characterization of $\mathrm{ZsGreen}^{+}$SC-derived cells and ZsGreen $^{+}$FAP-derived cells, single cell suspensions were stained with monoclonal antibodies for surface markers: biotinylated anti-lineage (CD3E, CD11b, B220, Gr1, Ter119) and streptavidinAPCCy7, CD45-BV785, CD31-BV421, CD34-e660, anti-Sca1-PECy7, anti-PDGFRa-BB700, anti-ITGA7-PE and Fixable Viability Stain 700 (FVS700). For PDGFRa expression analysis in C57BL/6 mice, cells were stained for the surface markers with anti-Ter119-FITC, CD45BV785, CD31-BV421, CD34-e660, anti-Sca1-PECy7, anti-PDGFRa-PE and FVS700. For mesenchymal stem cell mobilization, cells were stained with anti-lineage (CD3, B220, Ter119)-PerCpCy5.5, CD45BV785, CD11b-BV510, F4/80-PE, CD31-BV421, CD34-e660, and Sca1PECy7 (antibodies detailed in Table S3). Flow cytometry analysis was performed using a CytoFlex flow cytometer equipped with $405 \mathrm{~nm}$, $488 \mathrm{~nm}, 561 \mathrm{~nm}$ and $640 \mathrm{~nm}$ solid-state lasers (Beckman Coulter) or alternatively with a CyAn flow cytometer equipped with $405 \mathrm{~nm}$, $488 \mathrm{~nm}$ and $640 \mathrm{~nm}$ solid-state lasers. Data analysis was performed using FlowJo v10.6.1 software following compensation with single color controls.

MicroCT analyses

$\mathrm{NHO}$ volumes were measured in vivo in the Inveon PET-CT multimodality system (Siemens Medical Solutions, Inc.). Mice were anesthetized with a $2 \%$ isoflurane oxygen mixture. The parameters used were as follows: $360^{\circ}$ rotation, 180 projections, $80 \mathrm{kV}$ voltage, $500 \mu \mathrm{A}$ current, and effective pixel size $36 \mu \mathrm{m}$. After 3D image reconstruction, $\mathrm{NHO}$ volume was quantified in the Inveon Research Workplace (Siemens Medical Solutions, Inc.) as previously described. ${ }^{20,42}$

Histological analyses of mouse muscles

Dissected muscle was fixed in $4 \%$ paraformaldehyde for $24 \mathrm{~h}$ followed by decalcification in 14\% EDTA for 4 days. The solution was replaced with $10 \%, 20 \%$ and $30 \%$ sucrose/PBS every $24 \mathrm{~h}$. Muscles were mounted in optimum cutting temperature compound (OCT), frozen in isopentane in liquid nitrogen and stored at $-80^{\circ} \mathrm{C}$. Muscle samples were sectioned at $8 \mu \mathrm{m}$ using a Leica Cryostat CM1950. Every $8^{\text {th }}$ section was stained with hematoxylin \& eosin and examined for the presence of heterotopic ossification (HO). Slides consecutive to those with confirmed $\mathrm{HO}$ were subsequently subjected to immunofluorescence staining. After antigen retrieval with mild Proteinase $\mathrm{K}$ digestion $\left(50 \mu \mathrm{g} \cdot \mathrm{mL}^{-1}\right.$ Proteinase $\mathrm{K}$ (Ambion) for $2 \mathrm{~min}$ ), the sections were incubated for $10 \mathrm{~min}$ in PBS-Triton $0.5 \%$ and subsequently blocked for $1 \mathrm{~h}$ with $10 \% \mathrm{FBS} / 10 \% \mathrm{NGS}$ in $0.1 \%$ Tween 20 Tris- $\mathrm{HCl}$ buffered saline (TBS-Tween 0.1\%). The sections were incubated with primary antibodies (collagen type I (US Biological C7510-13), osteocalcin (EnzoLife Sciences ALX-210-333) or rabbit lgG control (Thermo Fisher 31235) diluted to $1 \mu \mathrm{g} \cdot \mathrm{mL}^{-1}$ in TBS-Tween $0.1 \%$ for $1 \mathrm{~h}$ at room temperature. The sections were washed with TBS-Tween $0.1 \%$, incubated with biotin-labeled goatanti-rabbit lgG secondary antibody (Vector Labs) for 20 min, washed and incubated with Alexa Fluor 647-labeled streptavidin (Thermo Fisher) for $20 \mathrm{~min}$. After counterstaining with 6-diamidino-2phenylindole (DAPI) at $0.5 \mu \mathrm{g} \cdot \mathrm{mL}^{-1}$ in TBS-Tween $0.1 \%$, the sections were mounted with ProLong ${ }^{\mathrm{TM}}$ Gold Antifade Mountant mounting medium (Thermo Fisher). Images of histological stains were captured at 20X magnification using an Olympus VS120 Slide scanner Microscope. Fluorescent images were captured on a Perkin Elmer Vectra III Spectral Scanner Microscope and spectrally unmixed using InForm software (Perkin Elmer) or an Olympus BX63 Upright Epifluorescence microscope. The number of osteocalcin ${ }^{+} \mathrm{NHO}$ nodules was counted in both $\operatorname{Pax}^{\mathrm{ZsG}}(\mathrm{n}=4)$ and Prrx $1^{\mathrm{ZsG}}(\mathrm{n}=3)$ mice. Two sections from the same mice $(>120 \mu \mathrm{m}$ apart) were stained, quantified and recorded in relation to the presence or absence of ZsGreen ${ }^{+}$cells.

Inhibition of BMP-2 signaling by LDN-193189 in vitro Bone marrow mesenchymal cells ${ }^{21}$ were seeded in a 96-well plate $\left(1.5 \times 10^{3}\right.$ cells per well) and maintained in aMEM $+20 \%$ FCS $+1 \%$ PSG until reaching confluence. The medium was then replaced with osteogenic medium [aMEM $+20 \%$ FCS $+1 \%$ PSG containing $\beta$-glycerophosphate $\left(10 \mathrm{mmol} \cdot \mathrm{L}^{-1}\right)$, phospho-ascorbic acid $\left(200 \mu \mathrm{mol} \cdot \mathrm{L}^{-1}\right), \quad \mathrm{CaCl}_{2} \quad\left(2 \mathrm{mmol} \cdot \mathrm{L}^{-1}\right) \quad$ and dexamethasone $\left.\left(0.2 \mu \mathrm{mol} \cdot \mathrm{L}^{-1}\right)\right]$ and recombinant human BMP-2 $\left(100 \mathrm{ng} \cdot \mathrm{mL}^{-1}\right)$ with additional LDN-193189 at 10,100, $1000 \mathrm{nmol} \cdot \mathrm{L}^{-1}$ or an equivalent volume of dimethyl sulfoxide vehicle. The medium was refreshed every 3 days. Mineralization on day 7 was quantified using Alizarin Red staining. ${ }^{21}$ In brief, cells were washed with PBS and fixed in 4\% paraformaldehyde for $30 \mathrm{~min}$. After removal of the fixative, the cells were air-dried overnight, stained with $1 \%$ Alizarin Red S solution at RT on a shaker for 5-10 min, washed with PBS and air-dried overnight. Staining was dissolved in $10 \%$ cetylpyridinium chloride (CPC) containing sodium phosphate $\left(10 \mathrm{mmol} \cdot \mathrm{L}^{-1}\right) \mathrm{pH} 7.0$ at RT on a shaker for $15 \mathrm{~min}$ and transferred to a new 96-well plate to measure observance at $562 \mathrm{~nm}$ using a Thermo Fisher Multiskan reader. 
Mouse muscle RNA extraction and qRT-PCR

Female $\mathrm{C} 57 \mathrm{BL} / 6$ mice underwent $\mathrm{SCl}$ or sham surgery followed by $\mathrm{i}$. $\mathrm{m}$. injections of CDTX or PBS. Four days after surgery, hamstring muscle samples were harvested and snap frozen in liquid nitrogen. Frozen muscle was homogenized in TRlzol with an IKA T10 basic homogenizer on ice for 30 seconds 3 times with 10 second intervals followed by incubation at RT for $30 \mathrm{~min}$. Tissue debris was removed after centrifugation at $12000 \times g$, and the supernatant was transferred to fresh tubes and mixed with a $1 / 5$ volume of chloroform. After centrifugation at $12000 \times g$ and $4{ }^{\circ} \mathrm{C}$ for $15 \mathrm{~min}$, the aqueous phase was transferred to a fresh tube, and RNA was precipitated by isopropanol, washed in 75\% ethanol, air-dried and dissolved in RNase/DNase-free water. RNA was quantified using a Nanodrop system (Thermo Scientific). cDNA was synthesized using a SeniFast CDNA synthesis kit following the manufacturer's instructions. mRNA expression was analyzed using a single-step reverse transcription quantitative real-time polymerase chain reaction (RTqPCR) TaqMan system. The reaction was prepared following the instructions of TaqMan ${ }^{\mathrm{TM}}$ fast PCR Master Mix and Bmp2, Bmp4, Bmp7 and Rps20 assays (Table S4). Reactions were read using an Applied Biosystems Viia7 Real-time PCR system. Ct values were normalized by the expression of the housekeeping gene Rps20 and are presented as ratios to that of housekeeping genes.

In vivo LDN-193189 treatments

C57BL/6 mice underwent SCl and CDTX intramuscular injection as indicated above on day 0 . Mice were treated with vehicle (6\% DMSO in PBS) or LDN-193189 (30 mg $\mathrm{kg}^{-1}$ ) via intraperitoneal (i.p.) injection twice daily from days $0-14$ or days $14-21$, which is effective in reducing $\mathrm{HO}$ volumes in a mouse model of $\mathrm{FOP}$ driven by the ACVR1 ${ }^{\mathrm{Q} 207 \mathrm{D}}$ missense mutation. ${ }^{44}$ Animals were randomly allocated to the vehicle or treatment groups after surgery (while the animals were still under anesthesia) but prior to treatment commencements. Therefore, grouping was not affected by recovery from surgery.

In vivo FAP apoptosis measurement

Mice underwent $\mathrm{SCl}$ or sham surgeries and CDTX injection and, samples were harvested 3 days post-surgery. Muscle cells were isolated as described above followed by surface marker staining: biotinylated anti-lineage (CD3ع, CD5, B220, CD11b, Gr1, Ter119), CD45-BV785, CD31-BV421, CD34-e660, Sca1-PECy7 and anti-ITGA7PE antibodies followed by streptavidin (SAV)-BUV395. After surface marker staining, the cells were washed in $1 \mathrm{X}$ PBS and then binding buffer $\left(10 \mathrm{mmol} \cdot \mathrm{L}^{-1} \mathrm{HEPES} \mathrm{pH}=7.4,150 \mathrm{mmol} \cdot \mathrm{L}^{-1} \mathrm{NaCl}, 5 \mathrm{mmol} \cdot \mathrm{L}^{-1}\right.$ $\left.\mathrm{MgCl}_{2}, 5 \mathrm{mmol} \cdot \mathrm{L}^{-1} \mathrm{KCl}, 1.8 \mathrm{mmol} \cdot \mathrm{L}^{-1} \mathrm{CaCl}_{2}\right)$. Next, the cells were stained with Annexin V-FITC (1/50 dilution) in annexin binding buffer at RT for 20 min. After excess Annexin $V$ was washed away, the cells were resuspended in Annexin binding buffer, and a 1/5 volume of 7AAD was added to the kit. Flow cytometry analysis was performed using a BD LSR Fortessa X20 cytometer equipped with $355 \mathrm{~nm}$, $405 \mathrm{~nm}, 488 \mathrm{~nm}, 561 \mathrm{~nm}$ and $640 \mathrm{~nm}$ solid-state lasers.

In vivo FAP proliferation measurement by BrdU incorporation For measurement of in vivo FAP proliferation during $\mathrm{NHO}$ development, mice underwent $\mathrm{SCl}$ or sham surgeries and CDTX injection. Two days prior to tissue harvest at day 14 post-surgery, the mice were given drinking water containing $0.5 \mathrm{mg} \cdot \mathrm{mL}^{-1} \mathrm{BrdU}$ (Sigma-Aldrich cat\# B5002) together with twice daily i.p. injection of $\mathrm{BrdU}$ for the last 2 days before tissue sampling. One mouse from the $\mathrm{SCI}+\mathrm{CDTX}$ group and one mouse from the sham +CDTX group were not treated with $\mathrm{BrdU}$ and used as a negative control for BrdU staining.

Muscle cells were isolated as described above followed by surface marker staining: anti-lineage (CD3ع, CD5, B220, CD11b, Gr1, Ter1 19)Pacific blue, CD45-BV785, CD31-PE, CD34-e660, and anti-Sca1-PECy7. The cells were then fixed and permeabilized using a BrdU flow kit (BD Pharmingen, cat\# 559619) following the manufacturer's instructions. The fixed cells were then treated with DNase I $(13 \mu \mathrm{g}$ per $1-2 \times 10^{6}$ cells $)$ in DNase reaction buffer $\left(10 \mathrm{mmol} \cdot \mathrm{L}^{-1} \mathrm{Tris}-\mathrm{HCl}\right.$, $0.5 \mathrm{mmol} \cdot \mathrm{L}^{-1} \mathrm{CaCl}_{2}, 2.5 \mathrm{mmol} \cdot \mathrm{L}^{-1} \mathrm{MgCl}_{2}$ in $\mathrm{PBS}, \mathrm{pH} 7.4$ ) at $37^{\circ} \mathrm{C}$ for $1 \mathrm{~h}$. BrdU incorporation in DNA was labeled with anti-BrdU-FITC monoclonal antibody in buffer containing $10 \mu \mathrm{g} \cdot \mathrm{mL}^{-1}$ blocking mouse IgG at RT for $1 \mathrm{~h}$. The cells were then washed and analyzed by flow analysis using a BD LSR Fortessa X20 cytometer.

Isolation of human BM-MSCs, PDGFRa ${ }^{+}$and $\mathrm{CD}_{5} 6^{+}$cells All $\mathrm{NHO}$ and muscle samples were obtained with the informed consent of the patients and approval from the People's Protection Committee (CPP approval $\mathrm{n}^{\circ}$ 09025) and from the National Commission for Informatics and Liberties (CNIL approval $\mathrm{n}^{\circ}$ Eyo1066211J). NHO biopsies were taken from the hips of 12 patients whose characteristics are provided in Table 1.

Muscle surrounding $\mathrm{NHOs}$ was collected from $\mathrm{NHO}$ surgical waste following their excision from patients with brain injuries, spinal cord injuries or strokes. NHO resection surgeries were performed at Raymond Poincaré Hospital (Garches, France). Muscle fragments were minced using a scalpel and small scissors, placed in a $50 \mathrm{~mL}$ Falcon tube and incubated in $1.5 \mathrm{mg} \cdot \mathrm{mL}^{-1}$ pronase (\#10165921001 Sigma-Aldrich) in a-MEM for $45 \mathrm{~min}$ in a $37^{\circ} \mathrm{C}$ water bath. After the addition of a-MEM supplemented with $15 \%$ FCS and $1 \%$ antibiotics, the cell suspension was filtered through a $100 \mu \mathrm{m}$ cell strainer followed by a $40 \mu \mathrm{m}$ cell strainer (BD Falcon). Isolated muscle progenitor cells (MPCs) were maintained in a-MEM supplemented with $15 \%$ FCS, $1 \%$ antibiotics and $10 \mathrm{ng} \cdot \mathrm{mL}^{-1}$ basic fibroblast growth factor (bFGF) (R\&D Systems). Human MPCs were trypsinized and incubated for 30 min with biotinylated anti-human PDGFRa (R\&D system) and CD56-PE (clone B159, BD Pharmingen) monoclonal antibodies in PBS with $2 \% \mathrm{FCS}$ and $2 \mathrm{mmol} \cdot \mathrm{L}^{-1}$ EDTA. The cells were washed and incubated for $30 \mathrm{~min}$ with streptavidin-APC/Cy7 and the viability dye 7-AAD (Sony). The cells were washed and filtered through a $30 \mu \mathrm{m}$ cell strainer (Sysmex) and sorted using a FACSAria III SORP sorter (BD Biosciences). PDGFRa ${ }^{+}$and CD56 ${ }^{+}$ cells were seeded at 3000 per $\mathrm{cm}^{2}$ in a-MEM supplemented with $20 \%$ FCS, $1 \%$ antibiotics and $10 \mathrm{ng} \cdot \mathrm{mL}^{-1} \mathrm{bFGF}$ (R\&D Systems).

BM-MSCs were isolated by plastic adhesion and expanded to $70 \%-80 \%$ confluence in a-MEM supplemented with $10 \%$ FCS and $1 \%$ antibiotics. Cells were subsequently seeded at 4000 per $\mathrm{cm}^{2}$.

Flow cytometry phenotyping of human PDGFRa ${ }^{+}$and $\mathrm{CD}^{+} 6^{+}$cells $\mathrm{PDGFRa}^{+}$and $\mathrm{CD}^{+} 6^{+}$cell suspensions (passages 4 and 5) were stained with monoclonal antibodies against the surface markers CD31-PE, CD34-APC, CD45-APC, CD73-PE, CD90-APC, and CD105$\mathrm{PE}$ (Table S3). Flow cytometry analysis was performed using a

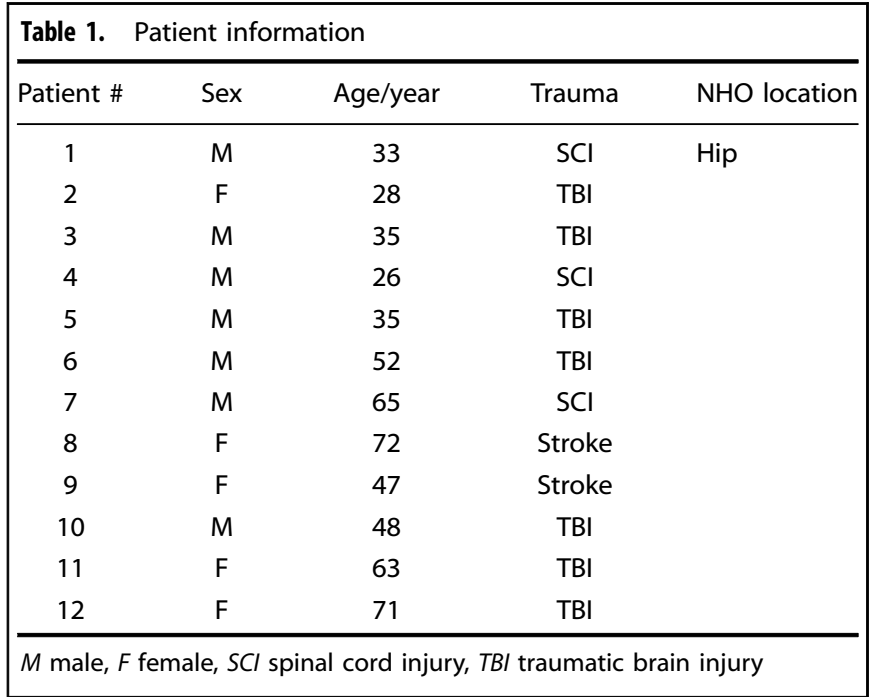


CytoFlex flow cytometer (Beckman Coulter). Data analysis was performed using FlowJo v10.6.1 software following compensation with single color controls.

qRT-PCR of human PDGFRa ${ }^{+}$and $\mathrm{CD}_{5} 6^{+}$cells

$\mathrm{PDGFRa}^{+}$and $\mathrm{CD}^{+} 6^{+}$cells (passages 3 to 5 ) were lysed in QIAzol (Qiagen) followed by chloroform/isopropanol total RNA extraction. Reverse transcription was performed using a Reverse Transcriptase Core Kit (Eurogentec). qRT-PCR was performed on a LightCycler 480 instrument (Roche) using a QuantiTect SYBR Green RT-PCR Kit and QuantiTect Primers (Qiagen). Three housekeeping gene mRNAs (GAPDH, PPIA, HPRT) were selected based on their expression stability using geNorm analysis. MYF5 and MYOD1 quantification was performed as the geometric mean of the quantifications obtained with each reference RNA.

In vitro osteogenic differentiation and quantification of mineralization of human cells

$\mathrm{PDGFRa}^{+}$and $\mathrm{CD}^{+}{ }^{+}$cells were seeded in 24-well plates at 3000 per $\mathrm{cm}^{2}$ in a-MEM supplemented with $10 \%$ FCS and $1 \%$ antibiotics. Once the cells adhered to the wells, the medium was replaced by aMEM supplemented with $10 \%$ FCS, $1 \%$ antibiotics and $0.052 \mu \mathrm{g} \cdot \mathrm{mL}^{-1}$ dexamethasone, $12.8 \mu \mathrm{g} \cdot \mathrm{mL}^{-1}$ ascorbic acid, and $2.15 \mathrm{mg} \cdot \mathrm{mL}^{-1}$ ß-glycerophosphate (Sigma-Aldrich) to induce osteogenic differentiation. Human recombinant OSM was added at $100 \mathrm{ng} \cdot \mathrm{mL}^{-1}$ (Miltenyi Biotec). The cells were cultured for 14 days at $37^{\circ} \mathrm{C}$ in a $5 \% \mathrm{CO}_{2}$ atmosphere, and the medium was changed twice a week. Quantification of mineralization was performed using Alizarin Red S staining. The cells were washed with PBS, fixed in $70 \%$ ethanol, quickly washed with distilled water and incubated for $5 \mathrm{~min}$ in $20 \mathrm{~g} \cdot \mathrm{L}^{-1}$ Alizarin Red S, $\mathrm{pH}=4.2$ (Sigma-Aldrich). The cells were washed with distilled water and dried. Alizarin Red S dye was extracted with $0.5 \mathrm{~mol} \cdot \mathrm{L}^{-1}$ hydrochloric acid and 5\% SDS and quantified by spectrophotometry at $405 \mathrm{~nm}$.

In vivo osteogenic assays with human cells

Subconfluent human BM-MSCs and PDGFRa ${ }^{+}$and $\mathrm{CD}^{+} 6^{+}$cells (2-3 amplification passages) were collected for subcutaneous implantation into the flanks of 10 -week-old male nude mice (Janvier Labs). Implants were prepared by mixing $2 \times 10^{6}$ cells with sterile 80-200 $\mu \mathrm{m}$ particles (60\% hydroxyapatite/40\% ß-tricalcium phosphate) (Graftys) and $100 \mu \mathrm{L}$ of human plasma in a $1 \mathrm{~mL}$ syringe as described. ${ }^{59}$ Control "plasma implants" did not contain cells. Ten microliters of $2 \% \mathrm{CaCl}_{2}$ in water was added to induce coagulation. Fifteen weeks after implantation, animals were euthanized, scaffolds were collected and fixed in $4 \%$ paraformaldehyde overnight at $4{ }^{\circ} \mathrm{C}$. The following day, scaffolds were washed with PBS and decalcified in $20 \%$ EDTA $\mathrm{pH}=8$ solution for $48 \mathrm{~h}$. Implants were washed with PBS and dehydrated with a graded series of ethanol solutions prior to paraffin embedding (Thermo Scientific).

Implant histology and immunohistochemistry

Paraffin sections $(4 \mu \mathrm{m})$ were dried, deparaffinized, and stained with hematoxylin eosin safranin (HES) (Dako). For immunohistochemical staining, $4 \mu \mathrm{m}$ paraffin sections were incubated with antigen retrieval citrate-based solution $\mathrm{pH}=9$ (Vector Laboratories) at $95^{\circ} \mathrm{C}$ for $15 \mathrm{~min}$. The sections were incubated in Bloxall blocking solution (Vector Laboratories) for $10 \mathrm{~min}$ to inactivate endogenous peroxidase. FC receptor blocking reagent (Innovex Biosciences) was then added for $45 \mathrm{~min}$. All sections were incubated in PBS-10\% FCS for 30 min with either anti-lamin $A / C$ antibody (dilution 1/200, clone EPR4100, Abcam) or anti-osterix/SP7 antibody (dilution 1/100, Abcam) diluted in PBS-5\% FCS-1.5\% BSA overnight incubation at $4{ }^{\circ} \mathrm{C}$. The sections were washed with PBS- $0.1 \%$ Triton and incubated in ImPRESS Reagent anti-rabbit lgG (Vector Laboratories) for 30 min. Then, the sections were washed with PBS-Triton $0.1 \%$ and incubated in HistoGreen substrate solution (Linaris) for $1 \mathrm{~min}$. Counter coloration was performed using Fast Nuclear Red (Vector
Laboratories). All sections were analyzed using a Pannoramic Midi II slide scanner and Case Viewer software (3D HISTECH, Ltd.).

\section{Statistics}

Statistical differences were calculated using the Mann-Whitney test or one-way ANOVA with Tukey's multiple comparison test with Prism v7 or 8 software (GraphPad software, La Jolla, CA).51. The data visualization in Fig. 4 was also performed using the Rstudio v1.1456, tidyverse and ggplot2 packages.

\section{ACKNOWLEDGEMENTS}

This work was partly supported by Project Grant 1101620 and Ideas Grant 1181053 from the National Health and Medical Research Council of Australia (NHMRC) and by award W81XWH-15-1-0606 from the Congressionally Approved Spinal Cord Injury Research Program of the US Department of Defense and by funds from the Mater Foundation. JPL is supported by Research Fellowship 1136130 from the NHMRC. This work was also partly funded by project grant 1101620 from the French Government Defense Procurement and Technology Agency (DGA - Direction Générale de I'Armement). The Translational Research Institute is partly funded by the Federal Government of Australia. The authors greatly acknowledge Sabrina Soaves, Bastien Rival and Muriel Nivet for technical assistance. The authors would like to thank the "Cochin HistlM Facility" for technical assistance of (Paris, France). They also highly acknowledge Prof. Philippe Denormandie and Dr. Laure Gatin (Service de Chirurgie Orthopédique, Hôpital Raymond Poincaré, Garches, France) and Guillaume Genêt for providing and coordinating access to $\mathrm{NHO}$ and muscle surgical residues. The authors also acknowledge the scientific and technical assistance at the Translational Research Institute: The University of Queensland biological resources TRI facility, histology facility, flow cytometry facility, microscopy facility and the preclinical imaging facility, which is supported by Therapeutic Innovation Australia (TIA). TIA is supported by the Australian Government through the National Collaborative Research Infrastructure Strategy (NCRIS) program.

\section{AUTHOR CONTRIBUTIONS}

J.-P.L., S.B., and M.C.L.B.K. conceived, designed and supervised the study. H.W.T., .D.G., S.M., K.A,. F.T., A.A., W.F., J.G.. M.E.G., D.C., B.N., M.S., and B.J. conducted the experiments, analyzed the data and interpreted the results. A.P., M.S., and F.G. contributed to scientific discussion, interpretation and experimental design. H.W.T., D.G., S.M., K.A., and W.F. prepared the figures for publication. H.W.T., D.G., M.C.L.B.K., S.B., and J.P.L. prepared the manuscript.

\section{ADDITIONAL INFORMATION}

Supplementary information The online version contains supplementary material available at https://doi.org/10.1038/s41413-022-00188-y.

Competing interests: The authors declare no competing interests.

\section{REFERENCES}

1. Ohlmeier, M. et al. Muscle localization of heterotopic ossification following spinal cord injury. Spine J. 17, 1519-1522 (2017).

2. Genet, F. et al. Troublesome heterotopic ossification after central nervous system damage: a survey of 570 surgeries. PLoS One 6, e16632 (2011).

3. Wittenberg, R. H., Peschke, U. \& Botel, U. Heterotopic ossification after spinal cord injury. Epidemiology and risk factors. J. Bone Joint Surg. Br. 74, 215-218 (1992).

4. Reznik, J. E. et al. Prevalence and risk-factors of neurogenic heterotopic ossification in traumatic spinal cord and traumatic brain injured patients admitted to specialised units in Australia. J. Musculoskelet. Neuronal Interact. 14, 19-28 (2014).

5. van Kuijk, A. A., Geurts, A. C. \& van Kuppevelt, H. J. Neurogenic heterotopic ossification in spinal cord injury. Spinal Cord. 40, 313-326 (2002).

6. Forsberg, J. A. et al. Heterotopic ossification in high-energy wartime extremity injuries: prevalence and risk factors. J. Bone Joint Surg. Am. 91, 1084-1091 (2009).

7. Sakellariou, V. I., Grigoriou, E., Mavrogenis, A. F., Soucacos, P. N. \& Papagelopoulos, P. J. Heterotopic ossification following traumatic brain injury and spinal cord injury: insight into the etiology and pathophysiology. J. Musculoskelet. Neuronal Interact. 12, 230-240 (2012).

8. Citak, M. et al. Risk factors for heterotopic ossification in patients with spinal cord injury: a case-control study of 264 patients. Spine 37, 1953-1957 (2012).

9. de I'Escalopier, N., Salga, M., Gatin, L., Genêt, F. \& Denormandie, P. Resection of heterotopic ossification around the hip after trauma. EFORT Open Rev. 4, 263-268 (2019). 
10. Vanden Bossche, L. \& Vanderstraeten, G. Heterotopic ossification: a review. J. Rehabil. Med. 37, 129-136 (2005).

11. Bradleigh, L. H. et al. Deep venous thrombosis associated with heterotopic ossification. Arch. Phys. Med. Rehabil. 73, 293-294 (1992).

12. Salga, M. et al. Sciatic nerve compression by neurogenic heterotopic ossification: use of CT to determine surgical indications. Skelet. Radio. 44, 233-240 (2015).

13. Genet, F. et al. Impact of the operative delay and the degree of neurologic sequelae on recurrence of excised heterotopic ossification in patients with traumatic brain injury. J. Head. Trauma Rehabil. 27, 443-448 (2012).

14. Genet, F. et al. Impact of late surgical intervention on heterotopic ossification of the hip after traumatic neurological injury. J. Bone Joint Surg. Br. 91, 1493-1498 (2009).

15. Haran, M., Bhuta, T. \& Lee, B. Pharmacological interventions for treating acute heterotopic ossification. Cochrane Database Syst. Rev. 18, CD003321 (2004)

16. Teasell, R. W. et al. A systematic review of the therapeutic interventions for heterotopic ossification after spinal cord injury. Spinal cord. 48, 512-521 (2010).

17. Alexander, K. A., Tseng, H.-W., Salga, M., Genêt, F. \& Levesque, J.-P. When the nervous system turns skeletal muscles into bones: How to solve the conundrum of neurogenic heterotopic ossification. Curr. Osteoporos. Rep. 18, 666-676 (2020).

18. Debaud, C. et al. Local and systemic factors drive ectopic osteogenesis in regenerating muscles of spinal-cord-injured mice in a lesion-level-dependent manner. J. Neurotrauma 38, 2162-2175 (2021).

19. Genêt, F. et al. Neurological heterotopic ossification following spinal cord injury is triggered by macrophage-mediated inflammation in muscle. J. Pathol. 236, 229-240 (2015).

20. Alexander, K. A. et al. Inhibition of JAK1/2 Tyrosine Kinases Reduces Neurogenic Heterotopic Ossification After Spinal Cord Injury. Front. Immunol. 10, 377 (2019).

21. Torossian, F. et al. Macrophage-derived oncostatin $M$ contributes to human and mouse neurogenic heterotopic ossifications. JCl insight 2, e96034 (2017).

22. Günther, S. et al. Myf5-positive satellite cells contribute to Pax7-dependent longterm maintenance of adult muscle stem cells. Cell Stem Cell 13, 590-601 (2013).

23. Montarras, D. et al. Direct isolation of satellite cells for skeletal muscle regeneration. Science 309, 2064-2067 (2005)

24. Sambasivan, R. et al. Pax7-expressing satellite cells are indispensable for adult skeletal muscle regeneration. Development 138, 3647-3656 (2011).

25 . Joe, A. W. et al. Muscle injury activates resident fibro/adipogenic progenitors that facilitate myogenesis. Nat. Cell Biol. 12, 153-163 (2010).

26. Wosczyna, M. N. et al. Mesenchymal stromal cells are required for regeneration and homeostatic maintenance of skeletal muscle. Cell Rep. 27, 2029-2035.e2025 (2019).

27. Lemos, D. R. et al. Nilotinib reduces muscle fibrosis in chronic muscle injury by promoting TNF-mediated apoptosis of fibro/adipogenic progenitors. Nat. Med. 21, 786-794 (2015).

28. Rebolledo, D. L. et al. Denervation-induced skeletal muscle fibrosis is mediated by CTGF/CCN2 independently of TGF-beta. Matrix Biol. 82, 20-37 (2019).

29. Contreras, O. et al. The cross-talk between TGF-beta and PDGFRalpha signaling pathways regulates stromal fibro/adipogenic progenitors' fate. J. Cell Sci. 132, jcs232157 (2019).

30. Shore, E. M. et al. A recurrent mutation in the BMP type I receptor ACVR1 causes inherited and sporadic fibrodysplasia ossificans progressiva. Nat. Genet. 38 525-527 (2006).

31. Hatsell, S. J. et al. ACVR $1^{\mathrm{R} 206 \mathrm{H}}$ receptor mutation causes fibrodysplasia ossificans progressiva by imparting responsiveness to activin A. Sci. Transl. Med. 7, 303ra137 (2015).

32. Dey, D. et al. Two tissue-resident progenitor lineages drive distinct phenotypes of heterotopic ossification. Sci. Transl. Med. 8, 366ra163 (2016).

33. Kan, L., Peng, C.-Y., McGuire, T. L. \& Kessler, J. A. Glast-expressing progenitor cells contribute to heterotopic ossification. Bone 53, 194-203 (2013).

34. Kan, C. et al. Gli1-labeled adult mesenchymal stem/progenitor cells and hedgehog signaling contribute to endochondral heterotopic ossification. Bone 109, 71-79 (2018).

35. Eisner, C. et al. Murine tissue-resident PDGFRalpha+ fibro-adipogenic progenitors spontaneously acquire osteogenic phenotype in an altered inflammatory environment. J. Bone Miner. Res. 35, 1525-1534 (2020)

36. Lees-Shepard, J. B. et al. Activin-dependent signaling in fibro/adipogenic progenitors causes fibrodysplasia ossificans progressiva. Nat. Commun. 9, 471 (2018).

37. Agarwal, S. et al. Inhibition of Hif1 a prevents both trauma-induced and genetic heterotopic ossification. Proc. Natl. Acad. Sci. USA 113, E338-E347 (2016).
38. Pignolo, R., Shore, E. \& Kaplan, F. Fibrodysplasia Ossificans Progressiva: Clinical and Genetic Aspects. Orphanet J. Rare Dis. 6, 80 (2011).

39. Murphy, M. M., Lawson, J. A., Mathew, S. J., Hutcheson, D. A. \& Kardon, G. Satellite cells, connective tissue fibroblasts and their interactions are crucial for muscle regeneration. Development 138, 3625-3637 (2011).

40. Logan, M. et al. Expression of Cre recombinase in the developing mouse limb bud driven by a Prxl enhancer. Genesis 33, 77-80 (2002).

41. Mitchell, K. J. et al. Identification and characterization of a non-satellite cell muscle resident progenitor during postnatal development. Nat. Cell Biol. 12, 257-266 (2010).

42. Tseng, H.-W. et al. Neurogenic heterotopic ossifications develop independently of granulocyte colony-stimulating factor and neutrophils. J. Bone Miner. Res. 35, 2242-2251 (2020)

43. Loder, S. J. et al. Characterizing the circulating cell populations in traumatic heterotopic ossification. Am. J. Pathol. 188, 2464-2473 (2018).

44. Yu, P. B. et al. BMP type I receptor inhibition reduces heterotopic ossification. Nat. Med. 14, 1363-1369 (2008).

45. Strong, A. L. et al. Bone morphogenetic protein ligand trap ALK3-FC attenuates osteogenesis and heterotopic ossification in blast-related lower extremity trauma. Stem Cells Dev. 30, 91-105 (2020).

46. Goloviznina, N. A. et al. Mesenchymal Stromal Cell-derived Extracellular Vesicles Promote Myeloid-biased Multipotent Hematopoietic Progenitor Expansion via Toll-Like Receptor Engagement. J. Biol. Chem. 291, 24607-24617 (2016).

47. Grenier-Pleau, I. \& Abraham, S. A. Extracellular vesicles tell all: how vesiclemediated cellular communication shapes hematopoietic stem cell biology with increasing age. Exp. Hematol. 101-102, 7-15 (2021).

48. Lecourt, S. et al. Characterization of distinct mesenchymal-like cell populations from human skeletal muscle in situ and in vitro. Exp. Cell Res. 316, 2513-2526 (2010).

49. Naldaiz-Gastesi, N. et al. Identification and characterization of the dermal panniculus carnosus muscle stem cells. Stem Cell Rep. 7, 411-424 (2016).

50. Fujimaki, S. et al. Notch1 and Notch 2 coordinately regulate stem cell function in the quiescent and activated states of muscle satellite cells. Stem Cells 36, 278-285 (2018).

51. Greenbaum, A. et al. CXCL12 in early mesenchymal progenitors is required for haematopoietic stem-cell maintenance. Nature 495, 227-230 (2013).

52. Mangiavini, L. et al. Fibrosis and hypoxia-inducible factor-1a-dependent tumors of the soft tissue on loss of von hippel-lindau in mesenchymal progenitors. Am. J. Pathol. 185, 3090-3101 (2015).

53. Krueger, K. C. et al. Characterization of Cre recombinase activity for in vivo targeting of adipocyte precursor cells. Stem Cell Rep. 3, 1147-1158 (2014).

54. Calo, $\mathrm{E}$. et al. $\mathrm{Rb}$ regulates fate choice and lineage commitment in vivo. Nature 466, 1110-1114 (2010).

55. Oishi, T. et al. Osteogenic differentiation capacity of human skeletal musclederived progenitor cells. PLoS One 8, e56641 (2013).

56. Couteaux, R., Mira, J.-C. \& d'Albis, A. Regeneration of muscles after cardiotoxin injury I. Cytological aspects. Biol. Cell 62, 171-182 (1988).

57. d'Albis, A., Couteaux, R., Janmot, C., Roulet, A. \& Mira, J.-C. Regeneration after cardiotoxin injury of innervated and denervated slow and fast muscles of mammals. Eur. J. Biochem. 174, 103-110 (1988).

58. Debaud, C. et al. Peripheral denervation participates in heterotopic ossification in a spinal cord injury model. PLoS One 12, e0182454 (2017).

59. Bouvet-Gerbettaz, S. et al. Adaptive immune response inhibits ectopic mature bone formation induced by $\mathrm{BMSC} / \mathrm{BCP} /$ plasma composite in immunecompetent mice. Tissue Eng. Part A 20, 2950-2962 (2014).

Open Access This article is licensed under a Creative Commons Attribution 4.0 International License, which permits use, sharing, adaptation, distribution and reproduction in any medium or format, as long as you give appropriate credit to the original author(s) and the source, provide a link to the Creative Commons license, and indicate if changes were made. The images or other third party material in this article are included in the article's Creative Commons license, unless indicated otherwise in a credit line to the material. If material is not included in the article's Creative Commons license and your intended use is not permitted by statutory regulation or exceeds the permitted use, you will need to obtain permission directly from the copyright holder. To view a copy of this license, visit http://creativecommons. org/licenses/by/4.0/

(c) The Author(s) 2022 